Portland State University

PDXScholar

$1-1-1983$

\title{
An internal review of a discipline: journal editors' opinions of paradigm development within speech communication
}

Laurie A. Houghton

Portland State University

Follow this and additional works at: https://pdxscholar.library.pdx.edu/open_access_etds Let us know how access to this document benefits you.

\section{Recommended Citation}

Houghton, Laurie A., "An internal review of a discipline: journal editors' opinions of paradigm development within speech communication" (1983). Dissertations and Theses. Paper 375.

https://doi.org/10.15760/etd.375

This Thesis is brought to you for free and open access. It has been accepted for inclusion in Dissertations and Theses by an authorized administrator of PDXScholar. Please contact us if we can make this document more accessible: pdxscholar@pdx.edu. 


\title{
AN INTERNAL REVIEW OF A DISCIPLINE: \\ JOURNAL EDITORS' OPINIONS OF PARADIGM DEVELOPMENT \\ WITHIN SPEECH COMMUNICATION
}

by

LAURIE A. HOUGHTON

A thesis submitted in partial fulfillment of the requirements for the degree of

\author{
MASTER OF SCIENCE \\ in \\ SPEECH COMMUNICATION
}

Portland State University

1983 
TO THE OFFICE OF GRADUATE STUDIES AND RESEARCH:

The members of the Committee approve the thesis of Laurie A. Houghton presented May 25, 1983.
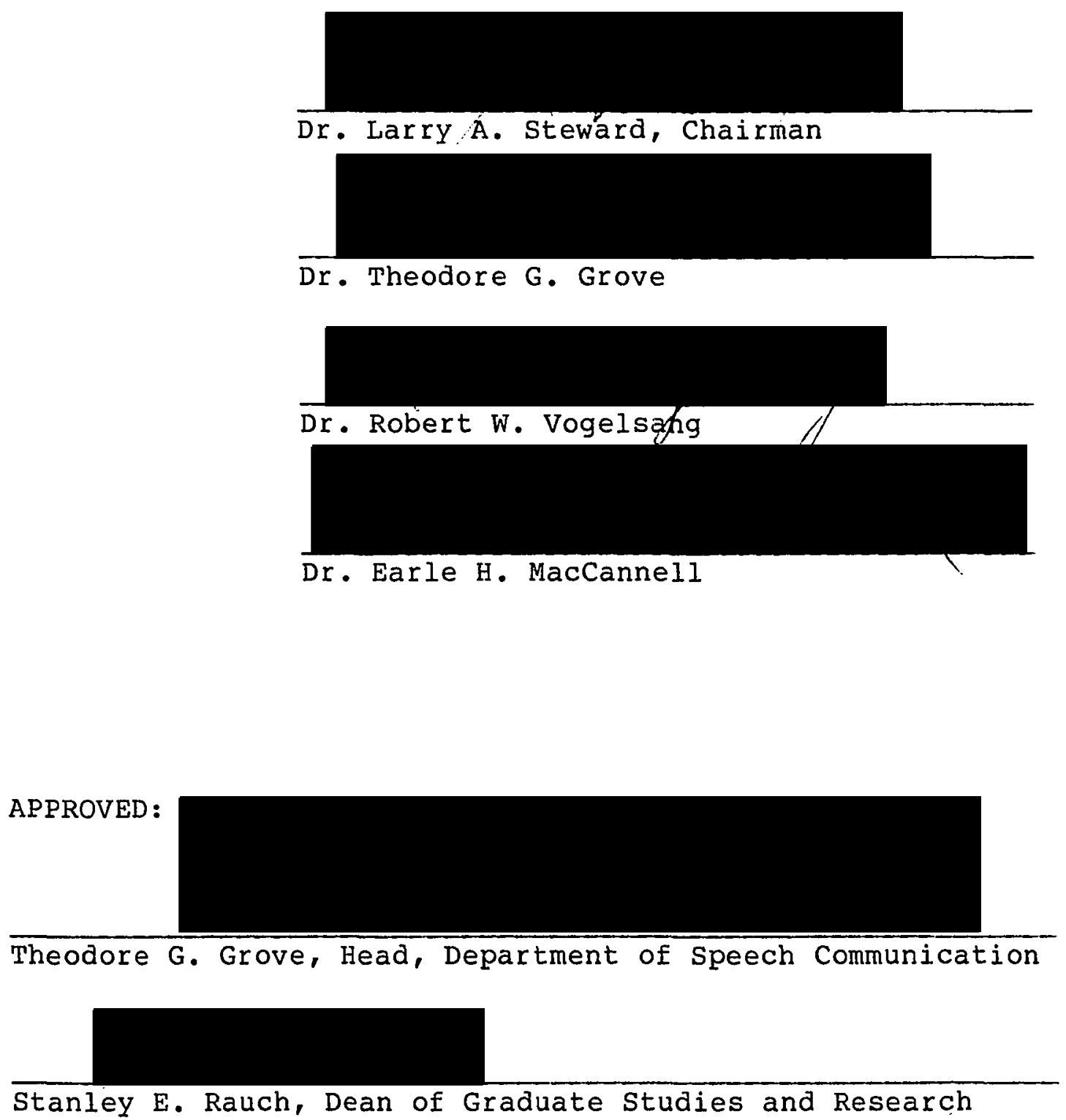
AN ABSTRACT OF THE THESIS OF Laurie A. Houghton for the Master of Science in Speech Communication presented May 25, 1983.

Title: An Internal Review of a Discipline: Journal Editors' Opinions of Paradigm Development within Speech Communication.

APPROVED BY MEMBERS OF THE THESIS COMMITTEE:
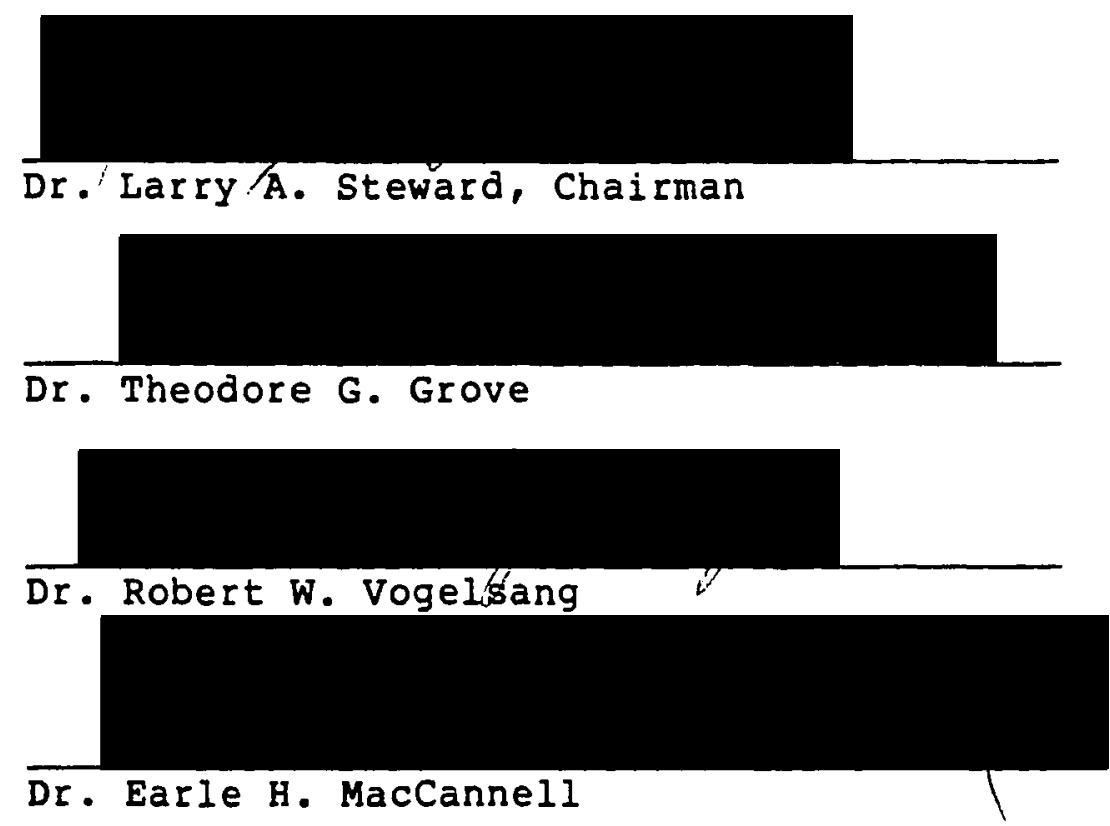

A review of the literature on paradigm development within academic fields revealed that researchers have drawn distinctions between disciplines with greater paradigm development (discussed as discipline-wide consensus) and disciplines with lesser paradigm development. Several of these investigations centered on paradigm development and 
evaluative criteria used by academic journal editors for judging scholarly work. The purpose of this study was to ascertain Speech Communication journal editors' opinions of paradigm development within their field.

A two-part survey was developed and mailed to eleven editors of the major Speech Communication journals. Data generated from the survey were analyzed using a descriptive methodology. Part $A$ of the questionnaire was a partial replication of Beyer's (1978) research concerning journal editors from ten major journals in four disciplines: Physics and Chemistry (greater paradigm-developed fields), and Sociology and Political science (lesser paradigmdeveloped fields). Degree of paradigm development within Speech Communication was examined through journal editor policies and practices concerning: difficulty in arriving at decisions for accepting or rejecting a manuscript, article length, manuscript revision, and length of time between manuscript submission and publication. The mean, range, and mode statistics were used to derive editorial practices within speech Communication. Mean scores from four fields investigated by Beyer (1978) were then descriptively compared to mean scores from Speech Communication in order to see where Speech Communication fit on the continuum of greater to lesser paradigm development.

Part $B$ of the survey was initially tested through a Pilot study administered to five faculty members in the 
Department of Speech Communication, Portland State University. They were asked to "act as if they were editors of a major speech Communication journal" for the purposes of completing the questionnaire. Respondents were requested to answer several open-ended questions related to their views of paradigm development in the field and to comment as to whether or not they believed paradigm was an indicator of discipline maturity. Data were content analyzed. Responses to the Pj.lot Study assisted in the conceptual refinement and placement of questions in Part B. Part A and Part B were then combined in the survey of Editors questionnaire and administered to eleven speech Communication editors-inchief.

All of the editors completed and returned the survey. The results of the study showed that while speech Communication journal editors believe there are paradigms operating within the discipline, they indicated a concern that paradigm development could preclude the maintenance of an eclectic perspective. Therefore, they do not think that paradigm is a sign of discipline maturity. In addition, the editors expressed a desire to improve the quality of scholarship within the field but that some kind of organizing principle is needed to facilitate this improvement. Finally, based on the results of this study, the discipline of speech Communication was found to be a lesser-developed paradigm field. 


\section{ACKNOWLEDGMENTS}

I would like to express my thanks to the eleven journal editors who thoughtfully completed and promptly returned their questionnaires, to my thesis committee for their constructive evaluations and time, and to Judy ouchi who lent her critical eye and typing expertise to this project.

In addition, I would like to extend my deepest appreciation to the staff Mentors and Apprentices of Life Course Options, Inc. who have significantly contributed to my interest in this topic and career as a social science Research Activist. Finally, without the creative guidance and rigorous criticism provided by my Mentor, Bill Lewin, this project would not have been successfully completed. 
TABLE OF CONTENTS

PAGE

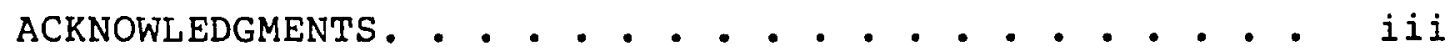

LIST OF TABLES . . . . . . . . . . . . . . . vii vi vi v

LIST OF FIGURE . . . . . . . . . . . . . . . . viii

LIST OF CHARTS . . . . . . . . . . . . . . . . viii

INTRODUCTION . . . . . . . . . . . . . . . . . 1

CHAPTER

I. LITERATURE REVIEW • . . . . . . . . . . . 6

The Importance of the Scholarly Journal. . 6

The Journal Editor and Refereeing System . Il

The Concept of Paradigm. . . . . . . 15

Paradigm Development and the Publishing

Process............ 20

Paradigm Development and Speech

Communication........... 26

I. METHODS AND PROCEDURES . . . . . . • . . 37

Hypotheses . . . . . . . . . . 37

Design of the study. . . . . . . . . 41

Sample . •. •. . • . . . - 41

Instrument Development . . . . . . . 43

Content Categories . . . . . . . 50

Pilot Study............. . 51

Methods of Analysis... . . . . . 54

Part A.............. 55

Part B.............. 56 
PAGE

Procedures... . . . . . . . 56

Mail Survey Procedures . . . . . . 57

III. RESULTS AND DISCUSSION . . . . . . . . . . 59

Part A............... . 59

Characteristics of speech

Communication Editors. .... . 60

Current Rate of Acceptance of
Accepted Manuscripts.... . . . 60

The Refereeing Process ...... . 65

Time Periods for Publication . . . . 72

Evaluative Criteria......... . 83

Editor Expectations.......... 87

Conclusions........... . . 89

Part B . . . . . . . . . . . 92

Question 1.......... . . 93

Question 2............. 94

Question 3........... . . . 97

Question 4............. 101

Question 5............. 103

Question 6............ . . 105

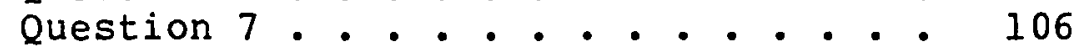

Conclusions. . . . . . . . . . 109

IV. LIMITS OF THE STUDY, SUMMARY AND

SUGGESTIONS FOR FUTURE RESEARCH . . . . . . • . . 112

Limitations of the Study . . . . . . 112

Summary. . . . . . . . . . . 116

Future Research. . . . . . . . 118

BIBLIOGRAPHY . . . . . . . . . . . . . . . 121

APPENDIX . . . . . . . . . . . . . . . . 130

A Letter to Pilot Study Participants . . . . 130

B Pilot Study, Part B. . . . . . . . . 131 
$v i$

PAGE

C Overview of Phone Conversation . . . . . . 134

D Letter to Survey Participants. . . . . . 135

E Survey of Editors Questionnaire. . . . . 136 


\section{LIST OF T'ABLES}

TABLE

PAGE

I Projected Patterns of Response to Part B of the survey of Editors. . . . . . . 49

II Current Rate of Acceptance and Patterns of Revision for Speech Communication Journals. . . . . . . . . . . . .

II The Refereeing Process and Rejection Rates in Speech Communication Journals. . . . 67

IV Time Periods between Manuscript Submission and Publication in Speech Communication Journals . . . . . . . . . . . .

$\mathrm{V}$ Time Periods between Manuscript Submission and Publication in Five Disciplines...

VI Number of Manuscripts Submitted Annually and Editor Tenure for Eive Disciplines. . . 76

VII Number of Manuscripts Submitted Annually and Editor Tenure for Speech Communication Journals... •. . . . . . . . . . .

VIII Article Length and Journal Content for Speech Communication Journals During 1981. • . . . . . . . . . . . •

IX Means of Article Length and Journal Content Eor Five Disciplines. . . . . . . . .

$X \quad$ Evaluative Criteria of Journals in Speech Communication ... . . . . . . 85

XI Evaluative Criteria of Journals in Five Disciplines............. 86 


\section{LIST OF FIGURE}

1. The Relationship of Research Hypotheses with Survey . . . . . . . . . . . 40

\section{LIST OF CHARTS}

I Current Rate of Acceptance and Patterns of Revision for Five Disciplines. . . .

II The Refereeing Process and Rejection Rates for Eive Disciplines. . . . . . . . . 


\section{INTRODUCTION}

In order for information generated through research to have any scientific or social value it must be made available to others. In other words, "communication" is the key. Historically, academic knowledge has been diffused through numerous formal and informal channels of communication. Since the seventeenth century, the scholarly journal, a formal communication channel, has significantly contributed to the dissemination of learned information. It is through the journal publication process that contributions to knowledge are publicly recognized. In addition, scholarly fields are initiated and developed through the process of formal information exchange in that new areas of research are identified and various groups of scholars pursue them. Overall, the scholarly journal contains much of the current written documentation of what is accepted as legitimate issues, methods, and trends within a given discipline (other forms of dissemination include books, and informal communication channels such as association meetings or conferences, etc.). In essence, contents of journals emanating from specific fields can be thought of as the archives of the discipline, where the journals are the disciplines because 
the journals store the cumulative knowledge of a particular community of scholars.

Since Thomas Kuhn's seminal work, The structure of Scientific Revolutions (1962), there has been increasing concern focused on the efficacy of scholarly research and reporting. This concern centers on the issue of the degree of paradigm development (often referred to as disciplinewide consensus) within various academic fields and the influence this has on "criteria" for evaluating scholarly work, particularly journal manuscripts. Although Kuhn only described the "development" of the physical and natural sciences, an examination of the literature revealed that this concern has mushroomed into a major debate in the social sciences as well (e.g., Eckberg and Hill, 1979; Beyer, 1978; Pfeffer, Leong, and Strehl, 1977; Yoels, 1974). However, paradigm development has yet to be widely examined within Speech Communication.

In light of the current interest in the concept of paradigm, this study was designed to (1) identify which paradigms may be found within the field of Speech Communication as reflected in the discipline's journals and (2) to determine the extent to which paradigm development affects formal communication channels within the discipline. While there are a number of definitions of paradigm, generally speaking, paradigm is defined here as an agreed upon perspective held by a community of scholars where theories, 
models, methods, instruments and language are commonly defined, described and utilized.

The "gatekeepers" of the journal publication process are the journal editors. They have the ultimate responsibility for accepting or rejecting manuscripts for publication. Because they are the pivotal link between scholars and manuscript selection, journal editors from eleven major Speech Communication journals were chosen as the subjects for this research project.

Editors were surveyed through a mailed questionnaire to gain their opinion of paradigm development within speech Communication. They were also asked to provide information regarding editorial policies and practices (e.g., use of referees in judging manuscripts, number of manuscripts rejected, what they thought the intent of their journal was, evaluative criteria in judging scholarly work, etc.). Speech Communication journal editor responses to the survey concerning editorial policies and practices were looked at in relation to each other and then in relation to Beyer's (1978) investigation of journal editors from ten major journals in the disciplines of Physics, Chemistry, Sociology and Political science.

Chapter one focuses on a review of the literature and provides a conceptual background for the study. Areas covered in the review include (1) the function served by the scholarly journal in academic disciplines, (2) the roles of 
journal editors and referees in manuscript selection, (3) the various definitions of paradigm, (4) paradigm development within different fields and (5) paradigm development in the discipline of speech Communication.

In chapter two, the methods and procedures of the research project are delineated. Two hypotheses and four sub-hypotheses are identified along with an explanation of the design of the study. A step-by-step account of the rationale and selection of the sample; the development of the research instrument; the parameters of the content categories used to evaluate editor opinion of paradigm development within speech Communication; the testing of the research instrument and revisions made as a result of a pilot study; the descriptive methods of analysis used to evaluate editor responses to the questionnaire; the methods of comparison of Beyer's (1978) results to this project; and the procedures used to conduct the mail survey are discussed.

Chapter three presents the results of the survey and an examination of speech communcation in relation to Physics, Chemistry, Sociology and Political Science regarding the degree of paradigm development in each discipline. The statistics used in the analysis of results reflect a descriptive and qualitative assessment and would not support any quantitative inference.

Information in chapter four concerns the limitations 
of the study, a summary of the study and suggestions for future research.

The significance of this research lies in its unveiling of the inner workings of a heretofore unexamined element of the field of speech Communication and, therefore, provides insight into its knowledge production and dissemination process. It is hoped that as a result of this thesis, further research into the "communication" of information within the scholarly community will be undertaken. Furthermore, it would be advantageous for the field of Speech Communication to include a previously ignored subject area--that of the analysis of communication among and between scholars as an area of academic pursuit. 


\section{CHAPTER I}

\section{LITERATURE REVIEW}

A review of the literature was undertaken in order to identify and understand the issues involved in manuscript selection within the journal publication process and to grasp the concept of paradigm development within academic fields. The following sections examine (1) the importance of the scholarly journal to academic disciplines, (2) the roles of journal editors and referees in evaluating manuscripts, (3) the concept of paradigm, (4) paradigm development and the publishing process, and (5) paradigm development and Speech Communication.

\section{THE IMPORTANCE OF THE SCHOLARLY JOURNAL}

The exchange of knowledge is integral to the development of an academic discipline. Cole and cole (1973) explained the importance of the free flow of scholarly information in this way:

Scientific advance is dependent on the efficient communication of ideas. Plainly, only those discoveries which come to be known can have an impact on the development of science. Only then do they become functionally relevant for the advance of science (p. 6).

Berardo (1981) has said of the publication process: 
The journal publication process plays a central role in the accumulation, dissemination, and certification of knowledge and the career histories of individual scholars (p. 771).

The scholarly journal came into existence during the seventeenth century as a communicative instrument of the newly established scientific societies. Prior to the journal, information was exchanged through sporadic letters, tracts, and books (Zuckerman and Merton, 1971). Because the journal was published as an extension of the Royal society, the information printed in it was considered to be reliable. Zuckerman and Merton (1971) reported on the significance of the journal in relation to the scientific society:

These organizations provided the structure of authority which transformed the mere printing of scientific work into its publication. From the earlier practice of merely putting manuscripts into print, without competent evaluation of their content by anyone except the author himself, there slowly developed the practice of having the substance of manuscripts legitimated, principally before publication although sometimes after, through evaluation by institutionally assigned and ostensibly competent reviewers. We see the slight beginnings of this in the first two scientific journals established just 300 years ago within two months of each other: the Journal des Scavans in January 1665; the Philosophical Transactions of the Royal Society, in March of the same year. The Journal was a conglomerate periodical which catalogued books, published necrologies of famous persons, and cited major decisions of civil and religious courts as well as disseminating reports of experiments and observations in physics, chemistry, anatomy and meteorology. The philosophical Transactions was a 'more truly scientific periodical...excluding legal and theological matters but including especially the accounts of experiments conducted before the (Royal) Society' (p. 68).

Crane (1972) has discussed the influence of institutionalized publications as contributing to the "exponential 
growth" of scholarly knowledge. She stated that it can be thought of as a "contagion" process where

...early adopters influence later adopters, which in turn creates an exponential increase in the numbers of publications and the numbers of new authors entering the area. The rate of expansion will vary depending upon the number of people with whom each scientist has personal contact (p. 23).

Ziman (1968) has stated that the journal is a benchmark of an evolving field:

The hallmark of a new discipline is the establishment of a specialized journal catering to the scholarly needs of its exponents. It constitutes an act of solidarity and solidity, and polarizes the subject around it (p. 105).

The creation and institutionalization of the journal, then, has been quite beneficial to the development of knowledge in that "...findings could be permanently secured, errors in the transmission of precise knowledge were greatly reduced and intellectual property rights registered in print" (zuckerman and Merton 1971, p. 69). Although it took awhile before scholars were motivated to share their research findings, the journal, more than any other development, established open communication among academics as a primary scientific norm.

One reward for sharing information is professional recognition; that is, giving and being given credit where credit is due. Hagstrom (1965) has explained that scholarly journals provide an outlet for "...an exchange of social recognition for information" (p. 13) and that this exchange "...binds donors and recipients in a community of values" 
(p. 23). Cole and Cole (1973) have shown that frequency of citation is a fairly stable measure of the impact of scholarly work and is strongly related to professional recognition. The Coles, focusing on the social stratificatinn of science, found that quality of research, not quantity, is a better predictor of citation frequency in the physical sciences. They state that because physical scientists' promotions often hinge on their publication prowess (as cited and listed in the Science Citation Index -- a cumulative record of cited scholarly works), citations are commonly used as criteria for judging professional work quality.

Publishing one's work in a scholarly journal not only gives one academic recognition, it also affords others the opportunity to build upon work done. In addition,

Getting published is a recognized and highly successful means for (a) enhancing personal recognition and prestige, (b) earning job security and advancement, (c) enhancing future chances of research funding and further publication, and (d) staking a publicly respected priority claim on some idea or discovery (Mahoney 1976, p. 79).

Ironically, relatively few involved in research "publish half of the total scientific literature" (Cole and cole 1973, p. 75). Ziman (1976) has also investigated the question of who is publishing and found:

...most 'scientists' have published no more than one scientific paper: only about 18 of the scientific community have published more than ten papers (which would be the least expected of someone of professional standing): only one scientist in a thousand publishes as many as a hundred papers in his lifetime...(p. 105). 
However, the small percentage of scholars actually publishing raises questions about the policies, procedures, and practices of academic publishing. What is the structure of the publishing process that encourages or discourages publication? What elements within the publishing system exert control over the process?

The preceding discussion has shown that the importance of the scholarly journal as a formal communicative tool for the development of an academic discipline and the documentation of thought can be discerned in the variety of functions it serves for the discipline. That is, (1) knowledge is promoted through swift publication and secured in history through written form, (2) the journal makes known important theoretical, empirical and hermeneutic advancement, (3) publishing one's work involves a certain degree of social interaction between investigators with similar interests, and (4) published articles act as encouragement for further work (Zuckerman and Merton, 1971). Accordingly, for most of its history, the scholarly journal has provided the major formal outlet and focal point for academic information sharing and has served, in this way, as the basis for knowledge dissemination and academic development within the disciplines. But, who decides what gets published? Manuscripts are submitted to journals for publication and are initially reviewed by journal editors. If the manuscript is acceptable at a basic level it is typically sent to referees 
to be either accepted or rejected. The following segment of this literature review examines the roles journal editors and referees assume as the screen in the publishing process.

II. THE JOURNAL EDITOR AND REFEREEING SYSTEM

While there are a number of components that make up the process of publication in journals - the referees, the manuscript, the author (Mahoney, 1976) - none is more important than the journal editor. As the gatekeeper to the journal, editors more than any other factor exert control over scholarly information dissemination and the access to the means of professional recognition for individual scholars. The task of the editor is to evaluate the authenticity, academic merit, and methodological soundness of a given work based on standardized criteria. It is through this process of manuscript evaluation and publication that scholarly norms are identified, established, transmitted, and maintained within a community of scholars. Mahoney (1976) succinctly describes the significance of the editor in this way:

...the most underrated figure in the science game is the journal editor. He controls the very life lines of science and in his hands may rest the fates of ideas as well as persons. In contemporary research, the unpublished thought is virtually impotent. Without communication to the professional community, it will seldom harvest either personal or technical advancement. It is the journal editor who ultimately decides what and who gets published (p. 88-89). 
The editor, however, is not the only evaluating force within the structure of journal pubiication; there is also the widely used mechanism of the referee system. Zuckerman and Merton (1971) define the system as:

...the systematic use of judges to assess the acceptability of manuscripts submitted for publication. The referee is thus an example of statusjudges who are charged with evaluating the quality of role-performance in a social system (p. 66).

This system of status-judges involves a form of peer review which, by its very nature, helps to instill and maintain academic standards and norms. Through their evaluations of performance and allocation of rewards (e.g., acceptance of a manuscript), referees are considered vital for the effective development of science. Ziman (1968) suggests that the value of referees lies in the maintenance of responsible scholarly inquiry and reporting:

The fact is that the publication of scientific papers is by no means unconstrained. An article in a reputable journal does not merely represent the opinions of its author; it bears the imprimatur of scientific authenticity, as given to it by the editor and the referees he may have consulted (p. 148).

As important as referees are to the manuscript evaluation process, there is no uniform procedure across journals for editor selection of referees. Gordon (1980) explained that in the earth, physical, and chemical sciences, editors expect referees to be "both up-to-date and competent in the specialism covered by the paper" (p. 263). In the social sciences both specialists and nonspecialists are incorporated into the review process (Smigel and Ross, 1970). 
Gordon (1980) identified three typical methods of referee selection:

The first system is that of maintaining a board, or panel, of editors, each of whom deals with a particular area within the journal coverage... The second method is that of maintaining a staff of full-time assistant editors who select referees using specially developed files containing the names and areas of specialized competence of researchers approved of by their senior part-time editors...The third factor affecting the frequency with which editors are able to select referees without reference to any other source is the extent of the editor's experience; both as an editor of the journal in question and as a member of the research community served by the journal (pp. 266-267).

Generally speaking then, referees are selected on the basis that they employ scholarly standards to evaluate manuscripts. Undertaking the responsibility of using "objective" criteria is what makes referees an integral part of the manuscript review process.

It is through editor and referee assessment that scholarly norms are identified, established, transmitted, and maintained within the community of scholars. However, as Lockwood (1977) has pointed out, scholarly standards and "norms of the field" are not clear nor agreed upon by all:

...scholarly standards are a very elusive set of qualities. While we can identify a number of component aspects, most of us would be at a loss to codify the absolutes that we - much less our colleagues in scholarship or scholarly publishing would defend as the scholarly standards by which we measure all scholarly things (pp. 6-7).

Thus, just what the criteria are for evaluating scholarly work is not easily identified and certainly may not be the same across disciplines, which brings up yet another 
problem--consensus in evaluative criteria.

Zuckerman and Merton (1971) illustrated the great diversity of editorial policies through an investigation of rejection rates across journals in the physical sciences, the social sciences and the humanities. They found that in fields where editors, reviewers, and authors do not share norms of what constitutes adequate scholarship, rejection rates were significantly higher. In particular, the humanities and the social/behavioral sciences had higher rates of immediate rejection at the editorial level than did the physical science journals. As zuckerman and Merton conclude:

The influx of manuscripts judged to be beyond all hope of scholarly redemption testifies to the ambiguity and the wide range of dispersion of standards of scholarship in the disciplines, all apart from the question whether the institutionally legitimated editors and referees or the would-be contributors are exercising better judgment. We do not know the comparative frequency of these reportedly unsalvageable manuscripts in different fields but the testimony of editors suggests that it is considerably higher in the humanities and the social sciences (p. 78).

Traditionally, the question of criteria has been discussed within the context of the concept of "paradigm development" within academic disciplines. Taken from Thomas Kuhn's The structure of Scientific Revolutions (1962), the notion of paradigm has captured the imagination and interest of a large number of scholars across the physical, natural and social sciences. While kuhn was primarily concerned with explaining the manner in which the hard sciences 
"developed and progressed," the question of "discipline development" has gained wide acceptance in a variety of fields. It is to this concept of paradigm and its relation to "agreed-upon criteria" for evaluating scholarly work that we now turn.

\section{THE CONCEPT OF PARADIGM}

In 1962 Thomas Kuhn's use of the term paradigm touched off a flurry of discussions that continue to this day. The dictionary definition of paradigm refers to pattern, model or example. Similarly, for Kuhn (1962), paradigm involves "puzzle solutions" which act as "exemplars" for solving further problems in normal science. Kuhn attaches this idea of "exemplar" to a broader explication of paradigm when he describes it as "...the entire constellation of beliefs, values, techniques, and so on shared by the members of a given community" (Kuhn 1970, p. 175). He combines the above ideas in his overall definition of the term, as: "...universally recognized scientific achievements that for a time provide model problems and solutions to a community of practitioners" (Kuhn 1970, p. viii). Thus, exemplar and world view/organizing principle appear important elements for Kuhn regarding his notion of paradigm. However, a great controversy concerning the precise definition of paradigm has raged since the first publication of his book in 1962.

It appears that greatest agreement about the term, 
"paradigm," centers around the fact that there is very little agreement as to what Thomas Kuhn meant (both in terms of definition and its intended application) when he used the term to characterize the scientific development of a discipline. In the forthcoming discussion, "paradigm" will be used as though there is some sort of scholarly consensus as to what the word describes. Moreover, this section will not consider the validity of Kuhn's overall analysis of revolutionary versus normal science, but rather, how the community of scholars have appropriated his idea of paradigm to describe the state of the art of their respective fields.

In an analysis of Kuhn's idea of paradigm, Margaret Masterman (1970) attributed three general conceptual frameworks for paradigm: (1) metaparadigm, (2) sociological, and (3) construct, based on twenty-one different ways Kuhn referred to paradigm. Masterman explained that paradigm used in the metaparadigm sense refers to a metaphysical world-view. This understanding is typically surmised fiom Kuhn's reference to "...a set of beliefs,...a myth...a new way of seeing...an organizing principle governing perception itself..." (Masterman 1970, p. 65). The sociological sense of paradigm is alluded to in Kuhn's description of a set of habits and "concrete scientific achievements" (Kuhn 1962, p. 10-11). Furthermore, in the sociological and metaparadigm senses, paradigm is prior to theory, at times being all pervasive (e.g., almost ideology), and in no way equates 
with theory. The construct perspective of paradigm, however, is explained by Masterman to be "less than a theory" (p. 67). The csonstruut view of paradigm relates to "exemplar", where the artifacts of research (e.g., textbooks, instruments, etc.) aid in subsequent puzzle solving. Masterman cites construct as the "real" explanation of Kuhn's use of paradigm. She concludes that many scholars have embraced the metaparadigm sense of paradigm and have therefore missed the true contribution of Kuhn's promise.

In contrast to Masterman, Gutting (1980) finds Kuhn's definition of paradigm to be explicit. He refers to the definitions given by Kuhn and explains that the key to paradigm lies in the censensus of the community of scholars encompassing the three "senses" Masterman identified (metaparadigm, sociological, construct). Gutting contends that paradigm should not be pigeonholed to given "rules" since the idea itself far exceeds such limitations. In addition, Gutting's explanation of Kuhnian consensus emphasizes that it does not equate with mere "agreement", but rather, an "unquestioned" acceptance of theory and method by a community of scholars which virtually negates the need for further conversation. This "consensus", then, frees the discipline's practitioners to address the business at hand; that is, puzzle solving within the paradigm. Gutting explained that consensus is derived from "...concrete instances of highly successful scientific practice that exemplifies the 
way science is done within that oiscipline" (p. 14).

Based on an analysis of the Iiterature pertaining to the use to which the concept of paradigm has been put, it is Gutting's broader and more inclusive interpretation of consensus that is most popular. This conseptualization of paradigm has been utilized most frequently within the social sciences. Many social scientists have embraced "paradigm development" as a way to measure discipline maturity.

As an example, Eckberg and Hill (19;9) analyzed the use of paradigm in Sociology. They examined twelve sets of "paradigms" identified within the field (Westhues, 1976; Bottomore, 1975; Ritzer, 1975; Denisoff, Callahan and Levine, 1974; Lehman and Young, 1974; Sherman, 1974; Carroll, 1972; Effrat, 1972; Kuklick, 1972; Walsh, 1972; Douglas, 1971; Friedrichs, 1970) and determined that none of these reviews of the field adequately demonstrated either exemplar or consensus definitions of paradigm. They concluded that sociology does not hava paradigms and, therefore, is not a mature discipline. They further concluded that studies attempting to incorporate the Kuhnian perspective of paradigm as a measure of the maturity of sociology are misguided. In their view, sociology is not a mature discipline. Gutting (1980) also evaluated the degree of paradigm development within the social sciences using his definition of paradigm as consensus. His conclusion was that consensus within the social sciences has been cursory 
at best, consequently, the social sciences are not "mature" sciences.

Discipline maturity in this sense has been operationalized to mean the degree of consensus within a field regarding rules, procedures, and standards for evaluation and the influence this consensus has on the use of "universalistic" or "particularistic" criteria in evaluating scholarly work. Universalism (or the use of universalistic criteria) means that, within the exercise of scholarly roles:

actors should make judgments based on scientific considerations of merit, rather than on particularistic and ascriptive criteria determined by personal preferences of the judge or characteristics as ciated with a person being judged, such as social background, sex, status, or membership in a particular group (Beyer 1978, p. 68-69).

Particularism refers to subjective evaluative criteria based on the author's social and professional status rather than the merit of his/her work. A manuscript is judged according to who the author is (e.g., "institutional affiliation, personal knowledge of the person, and position within the professional association" Beyer 1978, p. 73) not by what he/she has contributed. On the other hand, universalism assumes the existence of generally held criteria within a scholarly field or across fields that can be generally applied. This means that different scholars would come to similar conclusions when judging a given piece of scholarly work. The degree of consensus (or paradigm development) within a field "determines the degree to which universal- 
istically held criteria exist" upon which schulars can base their juagments concerning the work of other scholars (Beyer 1978, p. 69).

It is this interpretation of paradigm, that is, as an indicator of discipline maturity as evidenced in disciplinewide consensus regarding standaras for evaluating schciarly work that has been linked to the publishing process. Consensus in these studies has been operationaized to mean journal editorial policies and practices (e.g., acceptance and rejection rates of manuscripts across disciplines where low rejection rates are used as indicators of universalism and paradigm development). It is these studies that are discussed in the next section of this literature review.

\section{PARADIGM DEVELOPMENT AND THE PUBLISHING PROCESS}

During the last ten years, there have been numerous research efforts to determine paradigm development within various disciplines in both the hard and soft sciences. In particular Beyer, 1978; Pfeffer, Leong and strehI, 1977; Yoels, 1974; and Lodahl and Gordon, 1972 were all interested in measuring degrees of paradigm development within their respective fields. In these studies, the "consensus" definition of paradigm development is emphasized. Research conducted by zuckerman and Merton (1971) concerning the refereeing process will also be included in this discussion. While their work does not explicitly address paradigm, other 
authors have linked zuckerman and Merton's discussion of consensus to paradigm.

Beyer (1978) examined editorial policies and practices among the major journals of physics, chemistry, sociology and political science in order to compare their degree of paradigm development. Paradigm development was found by measuring the extent to which these journals reflect the use of universalistic vs. particularistic criteria in judging scholarly manuscripts. Beyer's study elicited some high correlations between physical science paradigmatic development and the use of universalistic criteria. She also found that lesser developed paradigm fields used more particularistic criteria to judge submitted articles. Beyer points out that these findings are reflected in both the rate of acceptance and the length of time between submission and rejection or acceptance. That is, "the length of time between submission and publication is more than twice as long in the social sciences as it is for the physical science journals" (p. 80-81). Beyer concluded that:

...physical science editors and referees are concerned with rejecting a manuscript winich should have been published, while social science editors and referees are concerned with preventing publication of something that should have been rejected. They are looking for something in a submission that justifies not publishing the article, and given the low consensus in the social sciences over many issues, they usually find it (p. 81-82).

This conclusion is reflected in her measured acceptance rates: in Physics it is $65 \%$; in Chemistry it is 718 ; in 
Sociology, 138; and in Folitical scienco it is 138 (E. 77). In addition, the "clearly unacceptable" manuscripts were minimal in Physics and Chemistry, whereas, manuscripts which covered a questionable topic or were deficient in methodology or writing style were much more frequent in the social sciences.

Thus, Beyer, in her analysis of universalism and particularism within the four fields of scholarship found more consensus among the physical science journal editors who were assessed as employing more universalistic criteria to judge scholarly work. She cited low rejection rates; agreement on terms, definitions, symbols and comparisons; less space required per journal article; less manuscript revision; and shorter time periods between submissions and publication as indicators of consensus.

Pfeffer, et al., (1977) examined the use of particularism in three fields: Chemistry, Sociology and Political Science. Their data were generated from the contents of 15 journals (five from each discipline) over a time period spanning 1963 to 1972. They compared institutional affiliation and editor decisions to publish. The institutional affiliations of the editors, authors, and editorial board members were analyzed to assess its impact on evaluations of manuscripts and decisions to publish. They found that "uncertainty and dissensus increase the likelibood of particularistic decision-making" (p. 949). 
Yoels (1974) also considered farticularism in editorial policies as an indicator as a lack of paradigm development. He evaluated journal editorial appointmert patterns in seven disciplines (Physics, Chemistry, Biology, Economics, Psychology, Political science, and Sociology). He concluded from his data that the political underpinnings of the social sciences preempt their achieving consensus and therefore, they rely on particularism for their evaluative criteria when juaging scholarly work. Based on his study, Yoels maintains that there are no paradigms in the social sciences.

LodahI and Gordon (1972) measured the perceived degree of consensus within four academic fields. A questionnaire was sent to professors in physics, chemistry, sociology and political science. Respondents ranked seven disciplines according to their perceptions of paradigm development achieved in each field. Again, the physical and natural sciences were thought to have greater paradigm development than the social sciences. Lodahl and Gordon contend tinat: ...high consensus found in hich-paradigm fields enhances predictability in at least two ways: (1) it provides an accepted and shared vocabulary for discussing the content of the field; and (2) it provides an accumulation of detailed information (scientific findings) on what has been successful in the past (p. 6I).

Zuckerman and Merton (1971) also examined rates of acceptance and $r$ jection of manuscripts submitted to 83 scholarly journals from several disciplines. They found 
that, within the physical and natural sciences, there was more consensus than in the social sciences and more agreement on scholarly work in the social sciences than in the humanities. They reported relatively few rejections of manuscripts in the physical sciences versus an 808 rejection rate in the social science disciplines studied. Their data indicated that journals in the humanities have the highest rates of rejection followed by the social and behavioral sciences. The physical, chemical, and biological sciences had the lowest rates of rejection, "running to no more than a third of the rates found in the humanities" (zuckerman and Merton 1971, p. 75). Although Zuckerman and Merton never explicitly linked this conclusion to paradigm development or consensus, it is believed by many scholars that their research can be interpreted as a study of paradigm development (Berardo, 1981; Gutting, 1980; Ruben and Wiemann, 1979; Yoels, 1974). Zuckerman and Merton found that decision rules of accepting or rejecting manuscripts followed a pattern according to a given discipline. Beyer found this same phenomenon and related it to degrees of paradigm development. Zuckerman and Merton described it in this way:

There are intimations in the data also that the editors and referees of journals with markedly different rates of rejection tend to adopt different decision-rules and so are subject, when errors of judgment occur, to different kinds of error...The editorial staff of high-rejection journals evidently prefer to run the risk of rejecting manuscripts which the wider community of scholars... would consider publishable (or even, perhaps, important) ...rather than run the risk of publishing papers 
that will be widely judged to be sib-standard. The editorial staff of low-rejection journals, where external evidence suggests that the decisions of scientists to submit papers are based on standards widely shared in the field, apparently prefer to risk errors... of the second kind; occasionaliy to publish papers that do not measure up rather than to overlook work that may turn out to be original and significant...Put in terms reminiscent of another institutional sphere, the decision-rule in highrejection journals seems to be when in doubt, reject; in low-rejection journals, when in doubt, accept (p. 78).

Based on the above statement, Yoels (1974) concluded that the Zuckerman and Merton study should be categorized as an investigation of consensus. He remarked that:

...consensus or lack of consensus on scholarship is not necessarily synonomous with consensus or a lack of consensus on paradigms; however, the 'scholarship' of authors holding to paradigms other than one's own is often held to be suspect. To some extent, then, the two phenomena of 'consensus on scholarship' and 'consensus on paradigms' overlap (p. 265 ).

As can be seen from this review of the literature, in general, journal editorial practices are highly related to degree of consensus within a scholarly discipline. It can be concluded that, in those disciplines with less paradigmatic development and consensus, rejection rates are high, particularistic criteria are used more often in judging scholarly work, and paradigm dissensus leads to more variability and inequity in the review system. Thus, editorial decisions concerning acceptance cr rejection of a manuscript, and therefore the access to academic rewards based on peer recognition (e.g., number of published articles, frequency of citation by other autho:s, etc.), are far more 
unpredictable in disciplines with less consensus. For example, a number of investigators found that "eminent" authors were more likely to receive quick reviews and were less likely to be asked for major revisions of their work than less well-known scholars (e.g., Mahoney, 1976; Zuckerman and Merton, 1971; Merton, 1968; Cole and Cole, 1967). As zuckerman and Merton state:

Although rank and authority in science are acquired through past performance, once acquired, they then tend to be ascribed (for an indeterminate duration) (p. 81).

The general conclusion about paradigm development is that the physical and natural sciences operate within fairly well developed paradigms while the social sciences have not established such agreement. As a consequence, scholars within the social science disciplines would more likely be judged using particularistic criteria concerning the conduct, reporting, and evaluation of their research.

The obvious next question, then, is: To what degree does paradigm development or consensus operate within the discipline of Speech Communication? As stated earlier, this issue is still a relatively unexamined area in the field. The next section explores the implications of paradigm development for the field of Speech Communication.

\section{PARADIGM AND SPEECH COMMUNICATION}

Even though Speech Communication has been referred to as a developing scientific discipline (Miller, 1981; Tucker, 
Weaver, and Berryman-Fink, 1981; Marlier, 1980; Delia, 1979; Gouran, 1979; Bochner, 1977), its genesis can be traced to ancient Greece: "the earliest recorded theories of human communication are those of Plato and Aristotle in the fifth century B.C." (Harper 1979, p. 1). However, as an emerging discipline, speech Communication has been, for the most part, non-self-reflective (Ruben and Wiemann, 1979; Bochner, 1977). That is, it has yet to undergo a process of critical self-reflection. Why this is the case has not been fully explored but many attribute this lack of self-examination to the amount of disagreement regarding the "character" of the field itself among its practitioners. Speech Communication, however, was not always in this condition. During the '50's and '60's, the field could boast about the high degree of agreement concerning intellectual focus and scholarly direction evident in the discipline. Bochner (1977) has described the "state of the art" at that time:

Communication research was once a very orderly enterprise. Throughout the 1950's and '60's the building block view of science, first cultivated by the Vienna Circle and later championed by experimental social psychology, stood unchallenged as the philosophical and methodological edifice for scientific investigations of communication. Most communication research during this period was modeled on the studies conducted by Hovland's Yale communication research team in the post world war II era. The research paradigm was the experimental, linear causality model. Independent variables were manipulated and their single, additive, or joint impact on an isolated dependent variable was measured. It was assumed that scientific knowledge could be accumulated progressively and that the steady methodological accumulation of facts would withstand the tests of time (p. 324). 
Today, consensus of approach and certainty of methods are not part of the discipline's demeanor. The traditional dependence on already established disciplines, methods, and theories, has resulted in what Bochner (1977) has labeled Speech Communication's "identity crisis".

Historically, communication scholars cast in the scientific mold have relied on the theoretical and methodological advances of neighboring disciplines, e.g., social and clinical psychology, group sociology, psycholinguistics, and social anthropology, to guide their research. Over the years, this dependence grew into an intellectual bondage and resulted in a serious identity crisis still with us today (p. 329).

Based on an internal review of the discipline, it is clear that speech Communication professionals in the field have not settled on what communication is, nor is there agreement concerning which theories, models, or methodologies are appropriate for use within the discipline (Miller, 1981; Tucker, et al., 1981; Ruben and Wiemann, 1979; Bochner, 1977; Delia, 1977; Fisher, 1977; Pearce, 1977; Rossiter, 1977).

However, in spite of this seeming lack of consensus and confusion in definition, Speech Communication appears to be a widely expanding field. Paulson (1980) describes the strengths of the discipline as follows:

The vitality of speech communication may be seen in three areas: the expansion of published research, the recognition of the field for national educational planning, and the growth of doctoral study (p. 320).

He also commented on the growth in the number of speech 
Communication journals:

Since the Quarterly Journal of Speech was established in 1915, the number of journals devoted to publication of communication research has grown to thirteen, with an output in 1974, for example, of some 480 studies and articles (p. 321).

Bochner (1977) also had an opinion on the increasing expansion of the field:

There are more journals publishing communication research than ever. Some highlight social relevance; others focus on conceptual analysis; still others favor systems analysis or mathematical modeling; almost all publish empirical research. The historic tendency to scatter human communication research unsystematically across the behavioral and social disciplines may, as a result, soon begin to diminish... One note of optimism signified by the journals with communication in their titles is the emergence of a support system for communication researchers. A support system is important to a discipline because it makes possible a sense of community among scholars with common interests and goals. Only a few years ago, empirical researchers in speech communication looked with reverence at their counterparts in social psychology. If there has been any dramatic change among communication researchers it has been in their sense of competence, and confidence in the quality and importance of their scholarship (p. 331).

Speech Communication is an emerging discipline, commanding a wider and wider audience, involving greater numbers of scholars in its research and knowledge development. Rossiter (1977) characterizes speech Communication as a "discipline with a developing scientific community that is moving from the aparadigmatic stage into the preparadigmatic" (p. 72). Rossiter (1977) in his analysis of the status of Speech Communication's paradigmatic development has defined paradigm as: 
...a world view about how theoretical work should be done in a particular subject area which is shared by those who actually do theoretical work in that subject area. It includes agreements about: assumptions about the nature of the subject areas or phenomenon about which theory is being built; variables which are most important for study to understand the phenomenon about which theory is being built; and acceptable methods for supporting assertions about the phenomenon about which theory is being built ( $p .70$ ).

He describes "aparadigmatic" as the period before paradigm development and "preparadigmatic" as the period of building toward discipline maturity where "conflicting paradigms exist and are battling for supremacy within a discipline" (p. 71). Based on this literature review, it would appear that Rossiter's assessment is accurate. The question for this thesis, then is: What paradigms are in conflict within Speech Communication?

Several authors have delineated two primary schools of thought within the field of speech Communication. Bowers (1982) discusses the two as the "motion" school and the "action" school. Tucker, et al., (1981) influenced by Borden and Stone (1976) relate a similar dichotomy in their description of "behavioristic" and "humanistic" approaches to inquiry. In these labels and descriptions, the authors refer to the ideas as paradigms.

Bowers (1982) describes the two paradigms of speech Communication in this way:

In the 'motion' school scholars search for causes (or more loosely, covariates of communicative processes (cf. Cushman, 1977; Miller, 1978; Sanders \& Martin, 1975). Within this school, disagreements 
exist about the value of hypothetical constructs, the operationalization of constructs and the virtues of prediction versus explanation. Consensus exists within the school on the use of controlled observation and mathematical logics (to get from data to inference), though some scholars grant that in the exploratory stages of research mathematical logics are unjustified (e.g., Browning, 1978, using methods suggested by Glaser \& Strauss, 1967).

The 'action' school teems with diversity, disagreement, and even confusion. Disagreements exist about the role of conceptual analysis versus scrutiny of data, the meanings of central theoretical constructs (such as 'rule'), the necessity of desirability of constructs such as 'unique self,' and the possibility of general explanation. Consensus exists in the assumption that human intentionality is central to communication (pp. 19-20).

Tucker, et al., (1981) make similar distinctions where the behavioristic approach includes:

1. A mechanistic learning model

2. Behavior is externally controlled by the environment

3. Behavior is predictable because of environmental conditioning

4. Skinnerian approach

5. Speech communication as science/communication

6. Descriptive/Empirical/Experimental methodologies (p. 275)

and the humanistic approach refers to:

1. A cognitive emotional model

2. Behavior is internally controlled by the person

3. Behavior is unpredictable because of freedom of choice

4. Rogerian approach

5. Speech communication as art/rhetoric

6. Descriptive/Historical-Critical methodologies (p. 275).

One of the interests of this study was to determine if there were any other paradigms recognized within the discipline. For instance, would speech Communication journal editors identify a paradigm operating within the field, that 
is, a world view that elicits an adherence to specific theories, models, instruments, and language, that could not be pigeonholed in either the action/behavioristic or motion/ humanistic modes? Too, do journal editors recognize the two paradigms discussed in the literature as the paradigms of the field? These questions are based on the assumption that understanding the configurations of a discipline is an important achievement for the development of a discipline.

These questions are also important to the direction of scholarship. While membership in an emerging, or preparadigmatic, discipline can be an exciting and rewarding intellectual endeavor, confusion about standards for scholarship may inhibit the qualitative development of a field. Bochner (1977) has identified one of the main problems for scholars in emerging disciplines:

The absence of a monolithic framework poses a serious dilemma for communication scholars. Anyone who wishes to remain on the cutting edges of the discipline must keep abreast of a wide and diversified array of scholarship. Yet, one must not sacrifice depth for breadth, lest one be rendered incapable of differentiating the conceptually deep from the technically shallow (p. 325).

As has been shown in the previous discussion, dissensus within a discipline is not necessarily conducive to its progress.

To recapitulate, disciplinary development is based on the free exchange of ideas and, as such, effective communication among scholars may be inhibited by the conflicts concerning adequate scholarship. MacRae (1976) has said, 
"Disciplines, whether they are called 'sciences' or not, are organized systems of communication among trained persons and undergo modification through the contributions of those persons" (p. 6). Littlejohn (1982) underscores this point by stating:

...scholarship is fundamentally a social activity. By this I mean that scholarship is built on the work of others and is sustained through interaction within the community. We learn our methods from other scholars, and our ideas are tested and criticized by others. Theories develop, grow, and change based on the scrutiny of colleagues within a field (p. 243).

The significance of the journal, the primary formal communication channel of the disciplines, has been elaborated in the beginning of this literature review. Mullins (1973), in his examination of the publication process in relation to scientific innovation notes:

The social organization of science is built around oral and written communication...Changes in communication structure can produce changes in the structure of disciplines and specialities and eventual reorganization of the scientific community (p. 36).

Thus, the scholarly journal provides one of the most important forums for communication among academics. However, the journal publication process has virtually gone unexamined by speech Communication practitioners. Commenting on this dearth of scholarly interest in their own discipline's development, Ruben and Wiemann (1979) state:

The study of the growth, development, and maturation of academic disciplines, paradigms, and writings has attracted the interest of very few communication scholars. This is somewhat surprising since the process by which scholarly work is diffused among 
members of a field and becomes accepted is essentially communicative in nature ( $p .47)$.

Because Speech Communication is in its developmental stages and there is controversy surrounding the direction the field should take, it would seem to be a prudent step to begin to evaluate the issue of paradigm development as a means of addressing the qualitative growth of the discipline. As an unexplored area within the field, it is apparent that much needs to be done.

Since the editors of the journals within Speech Communication are the knowledge brokers and "gatekeepers" to scholarly publication, it is reasonable to assume that they could provide the most accurate information regarding the publishing process. Additionally, because of their central role in the disposition of manuscripts, it is fair to say that they also would be representative of the degree of paradigm development and consensus within the field. Editors are personally responsible for soliciting articles, screening manuscripts, selecting referees, corresponding with authors, and copy editing. The final rationale for selecting speech Communication journal editors as subjects in this exploratory research is the precedent set in the social sciences (cf. Beyer, 1978; Pfeffer, et al., 1977; Yoels, 1974; Crane, 1967).

This study, while limited in scope, is an initial step in such an evaluation. Such studies are vital to the field in that assessing the state of one's academic "art" aids in 
the future development and direction of the discipline by providing insight into the current conditions within the field. In addition, an adequate understanding of journal publication policies and practices in speech Communication are necessary if the discipline is to positively and constructively fulfill its knowledge production and dissemination function. Publication is more than mere reporting of research, it is a form of social interaction among a community of scholars that influences and is influenced by the social context. From this formal communication procedure comes the "knowledge" produced by the speech Communication community. It is for these reasons that Speech Communication should begin looking at the communication processes of scholars.

This thesis addresses the following questions: which paradigm (or paradigms) are operating within the field of Speech Communication and (2) to what extent does degree of paradigm development affect the formal communication channel of scholarly publications within the field? In addressing these questions, this study will (1) provide information and an understanding of the journal policies and practices in Speech Communication, a relatively unexplored aspect of the field, (2) generate information about paradigm development within the discipline, and (3) compare speech Communication practices to those of the social and natural science disciplines. As Ruben and Weimann (1979) stated: 
...Karl Marx noted in the first volume of Das Kapital, men often pay so much attention to the tangible products of their labors that they are blinded to the social relations and social processes out of which these products come. The domaine of scholarship is clearly no exception, and we believe that disciplinary self-reflexiveness is nowhere more needed than in communication. In other fields it may be a luxury; for communication, it is simply a necessity (p. 53).

The next chapter delineates the methods and procedures utilized in this study to answer the research questions. 


\section{METHODS AND PROCEDURES}

This research study was designed to explore journal editor opinion of paradigm development within the discipline of Speech Communication. The areas covered in the methods section of this chapter include the research hypotheses and design of the study. Two major hypotheses and four subhypotheses are explained. In addition, components of the design of the study are discussed including the sample, instrument development, content categories, a pilot study, and methods of analysis. Finally, the procedures section of this chapter describes the mail survey.

\section{HYPOTHESES}

There were two major hypotheses for this investigation: Hypothesis 1. If Speech Communication is at the stage of preparadigmatic development, then speech Communication journal editors will identify more than one paradigm operating within the discipline.

Bypothesis 2. If Speech Communication journal editors make evaluations within a preparadigmatic frame- 
work, then they will reject more manuscripts than journal editors in fields having greater paradigm development.

The context in which the first hypothesis is posited relates to aparadigmatic discipline development. Understanding which paradigms are competing will shed light on journal editor opinion of the state of the art of the discipline at this time. Part B of the survey of Editors questionnaire was developed to test hypothesis one (see Figure 1, p. 40). A description of the instrument used in this investigation will be delineated later in this chapter.

A further explanation of this study's second hypothesis is provided by Beyer's (1978) examination of paradigm development in four scientific disciplines. She offered four hypotheses that are utilized in this investigation as sub-hypotheses.

Because consensus is a key element in greater paradigm development, Beyer suggested that articles from fields with more developed paradigms would require less (if any) reworking than articles emerging from fields with less developed paradigms. Since consensus is the underlying component, Beyer stated:

Sub-hypothesis 1. Journals in fields with less developed paradigms will require more manuscript revision of authors than journals in more developed paradigms (p. 70).

An important aspect of publication is the decision making process of accepting or rejecting a given manuscript. 
A number of authors have developed the argument that within disciplines, consensus promotes communication among scholars, makes manuscript acceptance and rejection easier for editors and referees, and lessens conflict among scholars (Beyer, 1978; Lodahl and Gordon, 1973; 1972). It follows from these arguments (and the review of the literature, Chapter I) that the processes of decision-making concerning journal publication would also be facilitated by the presence of a highly developed paradigm. Theories, ideas, and presentation of findings must be effectively communicated by an author if the manuscript is to be judged acceptable for publication by both editors and referees. As Beyer states, "without accurate communication, evaluative decisions are harder to reach" (p. 70). Therefore, Beyer posited:

Sub-hypothesis 2. Editors of journals in fields with more developed paradigms will report less difficulty in arriving at the decision of whether to publish manuscripts than editors of journals in fields with less developed paradigms ( $p .70$ ).

In fields with less developed paradigms, authors will probably encounter the red tape of rewrites, resubmissions and copy-editing. This process of revision, a by-product of dissensus, will lead to longer time periods between original submission and final publication. Beyer hypothesized that:

Sub-hypothesis 3. Journals in fields with less developed paradigms will have longer time lags between submission and publication than journals in fields with more developed paradigms (p. 71).

Beyer notes that brevity is another variable linked to 
paradigm development. It is through agreement on terms, definitions, symbols and comparisons, that valuable journal space is made available to other concise scientists. Since a commoniy defined language is an attribute of greater paradigm development, Beyer arrived at this hypothesis:

Sub-hypothesis 4. Articles appearing in journals in fields with developed paradigms will be shorter than articles appearing in journals in fields with less developed paradigms (p. 70).

These four sub-hypotheses then, are contained within the second hypothesis and are specifically tested in Part $A$ of the Survey of Editors questionnaire. This survey will be explained in the following section of this chapter.

\section{FIGURE 1}

THE RELATIONSHIP OF RESEARCH HYPOTHESES WITH SURVEY $\frac{\text { Survey of Editors Part A }}{\text { tests: }}$

Hypothesis TWO Sub-hypothesis 1 Sub-hypothesis 2 Sub-hypothesis 3 sub-hypothesis 4

\section{Survey of Editors Part B} tests:

Hypothesis ONE

In the next segment of Chapter II the design of the study will be discussed. The design took several phases: determining the sample; developing the instrument; delineating content categories; creating, administering and analyzing a pilot study; and deciding on the appropriate methods of analysis. 
II. DESIGN OF THE STUDY

Due to the exploratory nature of this research project, descriptive methodology was used. It was assumed that the degree to which paradigms are operative within the discipline would be reflected in the editorial policies of journal editors in the field. In order to discover the nature and extent of paradigm development, a two-part questionnaire was developed to assess the criteria utilized by the journal editors involved. Half of the survey questionnaire is a partial replication of Beyer's (1978) research (see Chapter I, Literature Review). The other half of the questionnaire was developed for the purposes of addressing the first part of the problem statement: Which paradigms are operating within the discipline? The research sample, the survey instrument, content categories, the pilot study and the methods of analysis are explained in the paragraphs that follow.

The Sample.

Data were collected concerning the perceptions of journal editors-in-chief regarding the influence of paradigms in their profession on editorial policy in theix respective journals. Journal editors selected for inclusion in this study were chosen based on their editorship of a major journal within the discipline of speech Communication. Journals were identified by Tucker, et al., (1981) and 
partially by Bochner (1977), as important representatives of the field. Included in Bochner's review were three additional journals from other disciplines. Although these three journals add to the body of speech Communication research, they were excluded from this study because they did not fit the criteria of a speech Communication journal where articles are focused on theory, method, and application reflecting the rubric of the discipline of speech Communication. Two other discipline-related journals were excluded because of their specialized orientations: Philosophy and Rhetoric and the Journal of the American Forensic Association. Local interest groups and state-wide journals were also not included as subjects for this study. Speech Communication journals determined appropriate for this research project were:

1. Central States Speech Journal

2. Communication Education

3. Communication Monographs

4. Communication Ouarterly

5. Communication Research

6. Human Communication Research

7. Journal of Applied Communication Research

8. Journat of Communication

9. The Quarterly Journal of Speech

10. The Southern Speech Communication Journal

11. Western Journal of Speech Communication 
Although the sample used in this study would typically be considered as small, it comprises the major scholarly speech Communication journals and is therefore a substantial representative sample. The forthcoming discussion of the research design explains the creation and structure of the testing instrument.

\section{Instrument Development}

The Survey of Editors questionnaire designed for this investigation is a composite and is divided into two parts, $A$ and $B$ (see Appendix for an example of the survey). Part A of the questionnaire is derived primarily from Beyer's (1978) survey conducted during 1974. This part of the testing instrument involved gathering information concerning current publication practices, (e.g., the current rate of acceptance of accepted manuscripts, the referee process, time periods for publication, a ranking of criteria used by editors for evaluating submitted manuscripts, and some general publication information). Part $A$ is listed as follows:

Current rate of acceptance of accepted manuscripts \& require no revision

\& require minor revision, not resubmitted to referees

\& require minor revision, resubmitted to referees \& require major revision, resubmitted to referees \& require major revision, treated like new submission

\section{Refereeing process}

8 of manuscripts refereed

\& of manuscripts not refereed that are rejected

$\&$ of manuscripts refereed by more than one referee

$\&$ of manuscripts unanimously accepted by referees

\& of manuscripts unanimously rejected by referees

$\&$ of manuscripts leading to referee disagreement 
Time periods for publication number of months between submission and publication of a typical manuscript shortest interval to publication number of months between decision to publish and actual publication number of months required for publication process exclusively

\section{Evaluative criteria}

originality

logical rigor

mathematical/statistical rigor

compatibility with generally accepted disciplinary ethics

clarity and conciseness of writing style

relevance to current areas of research

- theoretical significance

positive findings

negative findings

replicability

- coverage of significant literature

— applicability to practical or applied problems

\section{General publication information}

number of manuscripts submitted annually

tenure of present editor

- tenure of previous editor

These sections in Part $A$ of the questionnaire pertain to the second hypothesis and four sub-hypotheses of this study where rejection rates were indicators of paradigm development.

Questions concerning personal information about the editor such as age, academic specialty, highest academic degree achieved, and institution of degree were asked in order to put the data gathered in context and to create a profile of speech Communication journal editors.

Four open-ended questions were added to Part $A$ of the survey that were not part of Beyer's original study. These questions evolved from a synthesis of both written informa- 
tion (journal articles) and personal conversations (telephone calls) with journal editors concerning their role and decision-making procedures. For example, in an article summarizing his tenure as editor, Friedrich (1981) explained that upon assuming the editorship of communication Education he had had some desires of improving the journal, expanding its readership, increasing manuscript contributions from teachers in primary and secondary schools, and so forth. His conclusion was that although he had worked diligently to achieve his goals, he was unable to effect the kind of change he had hoped for. Also, in conversations with editors in this study, information concerning unfulfilled editor expectations were volunteered. In order to achieve deeper insight into this aspect, it seemed appropriate to ask editors to explain: (1) What was your original intention for the direction and focus of your journal that you wished to display upon assuming your editorship; (2) What obstacles, if any, have you encountered in the realization of the above; and (3) Can you identify any changes or modifications in your original intent? The purpose of these questions was to gain an understanding of each editor's opinion of their appointed role and their personal assessment of their achievements of their respective editorial goals.

In addition, the personal conversations with the editors encouraged the inclusion of "unanimously accept" and 
"unanimously reject" to the refereeing process section (neither were in Beyer's survey). The fourth open-ended question also related to the refereeing process: (4) What are the procedures you use for handing referee disagreement? This particular question specifically relates to the gatekeeping role of the journal editor (see Appendix $E$ for questionnaire).

Part B of the Survey of Editors questionnaire was developed to test the first hypothesis of this study. Questions were generated from a review of the literature and were designed to extract Speech Communication journal editor opinion of paradigm development within the field. Since paradigm seems to be such an elusive term, a definition of paradigm was supplied. Because Charles Rossiter (1977) is a noted contributor to the field of Speech Communication, his definition of paradigm was used as a point of departure for answering the questions (see Rossiter's definition of paradigm in the Literature Review, pp. 29-30). Editors were asked to respond to the questions bearing Rossiter's definition in mind (see Table I, p. 49 for clarification of predicted patterns of response).

Question one asked: "What is your assessment of paradigm development within the discipline of Speech Communication as reflected in your journal? Do you think we have any paradigms?" Those responding "yes" to the first question were directed to answer question two; those answering "no" 
were directed to question four. Question two followed the premise of the first in that, if the editor agreed there were paradigms, did they influence his decision-making process? The second question stated: Former journal editor Felix Berardo of the Journal of Marriage and the Family contends that "the formula of a successful author is a quality manuscript based on research grounded in an established paradigm" (1981, p. 771). Do paradigms influence your editorial decisions and practices? Those answering "yes" were asked to explain "in what ways," those answering "no" were directed to guestion five.

Question three was primarily geared to "yes" respondents of guestion one and two. If the editor agreed there were paradigms, what were they and what did they imply? Question three asked: If you agree that there are operative paradigms as indicated in question one, would you label each one and describe its philosophical underpinnings? That is, what makes the paradigm you describe distinctive? Question three respondents were then asked to answer question seven. If an editor responded "no" to question one he was asked in guestion four to explain why he thought there were no paradigms. It is important to understand that while the term paradigm is used freely, its actual existence within certain disciplines is questionable. Therefore, it is necessary to learn what scholars, in this case journal editors, conclude as to the existence of paradigms within their 
field. Because a paradigm is popular today does not necessarily imply its blanket acceptance as a description of a discipline. Question four asked: If you believe there are no paradigms within the field of speech Communication, could you briefly outline your reasons for that conclusion?

If an editor answered question one "yes" and question two "no" he was directed to respond to question five which stated: If paradigms do not influence your editorial decisions and practices, what factors do guide your evaluation procedures? This question was asked to gain a better understanding of the editor's evaluation process. If, as Berardo (1981) suggested, an editor uses paradigm as an underlying evaluative criteria, then, he would identify those influences in question two. If, however, paradigm is not a mitigating influence, then, understanding what criteria aids in decisions to accept and reject a manuscript is important for understanding the knowledge exchange system.

Question six is almost identical to question five and was asked of those editors who answered "no" to guestion one and who responded to question four. This question was made separate for the purposes of clarity and for maintaining a consistent thread for the three possible modes of response (see Table I, p. 49).

Each editor was directed to answer question seven. This question asked: Do you think that paradigm development is important for the maturation of speech communication as 
an academic discipline? Why? Why not? As stated in the review of the literature, paradigm development has been linked to discipline maturity. Finding out if the editors of Speech Communication journals agree with this interpretation has merit for understanding the degree of consensus or dissensus in the discipline. What we are doing, where we are going, and how we should get there are queries at the heart of theoretical, experimental, and applied studies. Understanding editors' views of paradigm development within a discipline and their evaluation of paradigm as an organizing principle can help delineate what is or is not currently important for the development of a discipline.

Table I below is a graphic representation of the directed response patterns of editors' answers to questions contained in Part $B$ of the survey.

TABLE I

PROJECTED PATTERNS OF RESPONSE TO PART B OF THE SURVEY OF EDITORS

$\begin{array}{lll}\text { Response Pattern 1 } & \text { Response Pattern 2 } & \text { Response Pattern 3 } \\ \text { Questions: } & \begin{array}{l}\text { Questions: } \\ \text { Questions: }\end{array} \\ 1 \text { if "yes" go to } 2 & \text { I if "yes" go to } 2 & 1 \text { if "no" go to } 4 \\ 2 \text { if "yes" go to } 3 & 2 \text { if "no" go to } 5 & 4 \text { go to } 6 \\ 3 \text { go to 7 } & 5 \text { go to } 7 & 6 \text { go to } 7 \\ 7 & 7 \text { a } & 7\end{array}$

In order to explore the question posited in the first hypothesis of this study, content categories were developed for analyzing answers to Part B of the survey of Editors. 
The next segment of this thesis is an explanation of the content categories deemed appropriate for analyzing the data for Part $B$ of the questionnaire.

\section{Content Categories}

Three content categories were created to analyze the data generated from Part $B$ of the questionnaire. As mentioned in the preceding chapter, preparadigmatic development refers to a stage when a discipline is involved with competing paradigms (Rossiter, 1977). A review of the literature revealed discussions concerning primarily two paradigms (see discussion, pp. 30-31). Each paradigm has its own scenario of terms associated with it where the typical explanation supplies sufficient information to delineate one paradigm from another. Content categories developed for analyzing editor perceptions of paradigm development within the discipline of speech Communication were behavioristic and humanistic. A third category was reserved for data that could not reasonably fit into the other two categories. Content categories derived from the literature were assembled in this way:

Category one - Behavioristic

1. Interest in causal relationships

The remaining six variables were listed in the literature review and were taken from Tucker, et al., (1981). They reappear in this section for clarification.

2. A mechanistic learning model 
3. Behavior is externally controlled by the environment

4. Behavior is predictable because of environmental conditioning

5. Skinnerian approach

6. Speech communication as science/communication

7. Descriptive/Empirical/Experimental methodologies (p. 275)

Category two - Humanistic

1. Intentionality

2. Hermeneutic

The following variables are from Tucker, et al., (1981) and are also enumerated in the review of the literature.

3. A cognitive emotional model

4. Behavior is internally controlled by the person

5. Behavior is unpredictable because of freedom of choice

6. Rogerian approach

7. Speech communication as art/rhetoric

8. Descriptive/Historical-Critical methodologies (p. 275).

Category three - other

Any perspective that cannot reasonably be put into the two categories above.

After content categories were defined, a pilot study was administered to test the content validity of Part $B$ of the survey.

\section{Pilot Study}

A pilot study was conducted to determine the functional value of the questions in Part $B$ of the survey of Editors questionnaire. That is, did the questions ask the right questions in order to garner the information sought. Five faculty members in the Department of Speech Communication at Portland State University agreed to "act as if they 
were editors of a major speech Communication journal" for the purposes of completing the survey. The faculty members were requested to provide answers to the questions as well as to evaluate the content and structure of the questionnaire. The results of this pilot study helped improve the final questionnaire in two significant ways. First, respondents followed the projected patterns of response delineated in the questionnaire and illustrated in Table $I$. This confirmed the idea that for the most part, respondents were not encouraged to answer questions one way or another. That is, question bias was under control as much as possible. Second, the responses to the pilot study indicated a need to refine several questions and to relocate one question. Content analysis of the responses also suggested that the questions elicited the predicted response where what was being asked was being answered. This was determined by the ease to which responses fit the parameters of the a priori content categories. Each answer could be placed in the appropriate content category.

For example, one respondent labeled and described three paradigms he/she recognized were operating in the field: covering laws model, rules, and process-withinsystems paradigm. Broadly interpreted, these three approaches can be grouped within the two content categories: behavioristic and humanistic. Covering laws was described as a "cause/effect search to uncover laws, 'scientific' in 
the tradition, largely imported from the physical sciences." Therefore, covering laws was categorized as representing a behavioristic paradigm perspective (see Content Categories, pp. 50-51). Process-within-systems was also put into the behavioristic paradigm category since it was defined as "focus on organization and communication from General systems and Information Theory. Structure and functions are of interrelated systems components." On the other hand, the definition the respondent supplied for the rules paradigm gave evidence for categorizing it as humanistic. It was defined as "identification of regularities of rules of communication, rules, typologies and conditions of deviation from rules and latitude of definition of rules. Emphasis is on the role of human choice in outcome behavior." The role of "human choice" was the determining factor for describing this approach as interpretive. Literature concerning the "rules" perspective also affirms this conclusion (see Donohue, Cushman and Nofsinger, 1980; Cronen and Davis, 1978 ; Cushman, 1977; Cushman and Pearce, 1977; Pearce, 1973). Another example highlights the control of response bias of the questions. Responses to question seven regarding paradigm as a possible element contributing to discipline maturity could not be second-guessed based on the respondents' answers to the preceding questions. That is, while one may answer question one "yes", it did not necessarily follow that that same individual would answer question 
seven "yes". Pilot study respondents bore out this assumption. One respondent who answered question one "yes", answered question seven "no" and supplied this explanation regarding paradigm development as an important aspect of discipline maturation: "not in an absolute sense - as long as the specific assumptions are clearly stated and addressed by communicants." This answer suggested that paradigms may not be important for contributing to the development of the discipline. An additional "no" response from a "no" on question one, "no" on question seven respondent wrote: "Our discipline can prosper best by remaining broad based and unattached to any narrowing tendencies." This answer also fit into the predicted response pattern where the response indicates the status of the discipline as being aparadigmatic (without paradigm).

While the pilot study only pertained to Part $B$ of the questionnaire, two forms of analysis were used for examining responses to the entire survey. The following section explains the context in which the data for this investigation were analyzed.

\section{Methods of Analysis}

Due to the exploratory nature of the research project, two forms of descriptive analysis were employed for measuring responses to the Survey of Editors questionnaire: one form of analysis for Part $A$, and one for Part B. Measures of central tendency were used for evaluating Part $A$ of the 
questionnaire, thereby addressing the second hypothesis. Content analysis was used for analyzing answers to Part $B$ and for assessing the first hypothesis. Discussion concerning methods used for analyzing data for Part B will follow the explanation of those used for Part $A$.

Part A. For Part A of the questionnaire, Speech Communication journals were compared to one another to derive the mean, range, and mode of journal editor responses. To provide a comprehensive view, all three descriptive statistics were used since measuring only the mean does not explain extreme scores, the range does not explain the score of the average case, and the mode simply pinpoints multiple occurrences of one score over all the others. The mean scores of Part $A$ were then examined in relation to the mean scores generated from Beyer's research during 1974 and published in 1978. Her sample involved the ten leading research journals in four scientific disciplines (Chemistry, Physics, Sociology, Political science), two having greater paradigm development (Chemistry and Physics) and two having lesser paradigm development (Sociology and Political Science). In this study, mean scores from Beyer's analysis of the four disciplines were compared with the scores from Speech Communication journals in order to acquire a descriptive understanding of where the discipline of Speech Communication lies on the continuum of greater to lesser paradigm development. Although Beyer's work was done some nine years 
ago, it was assumed that paradigm development is irreversible. Therefore, eight years would either constitute a maintenance of a status quo of Beyer's measured paradigm development, or more rather than less paradigm development would have occurred.

Part B. To examine the implications of the first hypothesis, it was necessary to develop Part $B$ of the questionnaire. Lacking a standardized test designed to explore this hypothesis, the method of "Content Analysis" was selected for evaluating data generated from Part B. For this research project "Content Analysis is any research technique for making inferences by systematically and objectively identifying specified characteristics within text" (Stone, Dunphy, Smith and Ogilvie 1966, p. 3). Involved with this research method was developing categories (see pp. 50-51 for description of Content Categories), determining questionnaire text responses pertinent to concept categories, organizing and distributing data within categories, assessing the compilation of results and finally making inferences. After the pilot study had been administered, analyzed, and Part B of the questionnaire had been revised, procedures for carrying out the survey were then implemented.

\section{PROCEDURES}

The focus of this section is on the procedures used to conduct this research project. Since contacting editors in 
the sample took several phases, a full explanation of what took place is provided.

\section{Mail Survey Procedures}

"The boon of mail questionnaires is their low cost and the bane is their low response rate." (Warwick and Lininger 1975, p. 131). Recognizing that this caution was based on firm evidence, a non-traditional survey participation approach was taken. Since the sample involved only eleven editors, each editor was telephoned before the questionnaire was mailed out. Telephone calls were placed on November 30 and December 1, 1982 and the surveys were sent the day the particular call was made. In the telephone conversation, the researcher identified herself, briefly explained the intent and scope of the study and requested their assistance in filling out and returning the questionnaire. Each editor agreed to participate (see Appendix C for outline of telephone conversation). The questionnaires were sent with a cover letter and self-addressed, stamped envelope by certified mail so that the researcher would be able to confirm editor receipt of questionnaires. Eight out of eleven surveys were returned within ten days for an initial return rate of $72 \%$. Twenty-seven days after the first questionnaires were sent out, three replacement questionnaires were sent to non-respondents. All three were returned within twenty days. The overall response rate for this research 
project was 100\%. A summary report of the findings of this study was sent to interested respondents.

Using the methods and procedures described in this chapter, the investigation of Speech Communication journal editor opinions of paradigm development and journal policies and practices was undertaken. The next chapter discusses the results of this research project explaining in full detail the responses to parts $A$ and $B$ of the survey of Editors and what can be inferred from the results. 
CHAPTER III

\section{RESULTS AND DISCUSSION}

The results of this investigation are presented following the format of the survey of Editors questionnaire. With regard to Part A of the survey, speech Communication journals are discussed as they relate to each other and then in comparison to the four disciplines in Beyer's (1978) study. Measures of central tendency, the mean, the range and the mode statistics were used to assess editorial practices in speech Communication journals. Mean scores of Physics, Chemistry, Sociology, and Political Science derived from Beyer's (1978) study and speech Communication means derived from Part $A$ of the survey were examined to show degree of paradigm development in speech Communication. Data from Part $B$ of the survey were gathered from speech Communication editors (only) and were content-analyzed. Part A data are discussed in the paragraphs that follow and are illustrated in Tables and Charts. A discussion of Part $B$ results will follow those of Part $A$.

\section{PART A}

Part A of the survey of Editors questionnaire tested the second hypothesis of this investigation: If speech 
Communication journal editors make evaluations within a preparadigmatic framework, then they will reject more manuscripts than editors in fields having greater paradigm development. As was mentioned in Chapter II, Beyer (1978) presented four hypotheses that correspond and elaborate this study's second hypothesis and were therefore utilized as sub-hypotheses for this investigation. Each will be discussed in the next few paragraphs.

\section{Characteristics of Speech Communication Editors}

Preceding Part A of the Survey of Editors were questions concerning personal information about the editors of the journals included in this study. The mean age of the eleven editors was 48.6 years, ranging from 34 to 63 , and the mode was 45. All journal editors were male and all had Ph.D.'s. Only one of the eleven editors had a non-speech related academic specialty. Finally, the majority of editors ( 8 of the 11) received their degrees from universities situated in the midwest and the remaining three received their doctorates at universities in southeast, mountain, and west coast states.

\section{Current Rate of Acceptance of Accepted Manuscripts}

The current rate of acceptance of accepted manuscripts was examined using Beyer's (1978) hypothesis that became this study's sub-hypothesis l: "Journals in fields with less developed paradigms will require more manuscript revi- 
sion of authors than journals in more developed paradigms" (p. 70). For journals in Speech Communication the current rate of acceptance ranged from $8 \%$ to $27 \%$, a range of 198 (see Table II). The mean and mode were also 198 . In relation to the other four disciplines (as displayed in Chart I), the data show that speech Communication has a greater rate of acceptance than Sociology or Political science (both at $13 \%$ ). However, there is a large gap between the speech Communication acceptance rate of 198 and those of Physics at 658 and Chemistry at 718 .

Within the discipline of Speech Communication, seven out of eleven journals indicated that all articles are revised to one degree or another: the mean was $2 \%$, and the range was 0 to to $10 \%$ (see "no revision" category, Table II). This means that an average of only 28 of the manuscripts accepted do not require revision. This level of manuscript revision was noted by a previous editor of communication Quarterly. Benson (1979) stated, "If you expect to publish in speech communication, expect to be invited to revise" ( $p$. 10). In sharp contrast, those publishing in Physics (see Chart I) are requested to revise their manuscripts less frequently, where $46.5 \%$ require no revision.

On the average, 238 of speech Communication manuscripts are revised without needing to be resubmitted to referees. Within the discipline, however, the various journals have disparate policies on this issue as is evidenced 
TABLE II

CURRENT RATE OF ACCEPTANCE AND PATTERNS OF REVISION

FOR SPEEOH COMMUNICATION JOURAAL

\begin{tabular}{|c|c|c|c|c|c|c|c|c|c|c|c|c|c|c|c|}
\hline Verleble & & Journe & & & & & & & & & & & Moan & Range & Mode \\
\hline $\begin{array}{l}\text { Current rate } \\
\text { of ecceptance }\end{array}$ & $n=11$ & 8.0 & 21.0 & 19.0 & 17.0 & 26.0 & 19.0 & 23.0 & 8.0 & 19.0 & 20.0 & 27.0 & 19.08 & $27-8$ & 19.0 \\
\hline No revision & $n=11$ & 7.50 & .0 & 4.5 & .0 & .0 & 10.0 & .0 & .0 & 1.0 & .0 & .0 & 2.48 & $10-0$ & .0 \\
\hline $\begin{array}{l}\text { Minor revision, } \\
\text { not resubmitted } \\
\text { to referees }\end{array}$ & $n=10$ & 33.5 & .0 & 50.0 & .0 & 30.0 & 30.0 & 60.0 & -- & 10.0 & .0 & 10.0 & 23.48 & $60-0$ & .0 \\
\hline $\begin{array}{l}\text { Minor revision, } \\
\text { resubiltted to } \\
\text { referees }\end{array}$ & $n=10$ & .0 & 1.0 & .0 & 1.0 & .0 & 10.0 & 10.0 & -- & .0 & 15.0 & 30.0 & 8.18 & $30-0$ & .0 \\
\hline $\begin{array}{l}\text { Major revislon, } \\
\text { resubmitted to } \\
\text { reforees }\end{array}$ & $n=10$ & 50.0 & 65.0 & 45.0 & 15.0 & 60.0 & 30.0 & 25.0 & --- & 40.0 & 75.0 & 30.0 & 42.04 & $75-15$ & 30.0 \\
\hline $\begin{array}{l}\text { Major rovision, } \\
\text { treated IIke } \\
\text { new submission }\end{array}$ & $n=10$ & 10.0 & 20.0 & 25.0 & 15.0 & 10.0 & 20.0 & 5.0 & --- & 39.0 & 10.0 & 30.0 & 18.48 & $39-5$ & 10.0 \\
\hline
\end{tabular}

"Data were analyzed using descriptive statistlics and are not meant to support statistlcal inference. 
CHAKT I

CURRENT KATE OF ACCEPTANCE AND PATTERNS OF REVISION FOR FIVF IISCIPLINES*

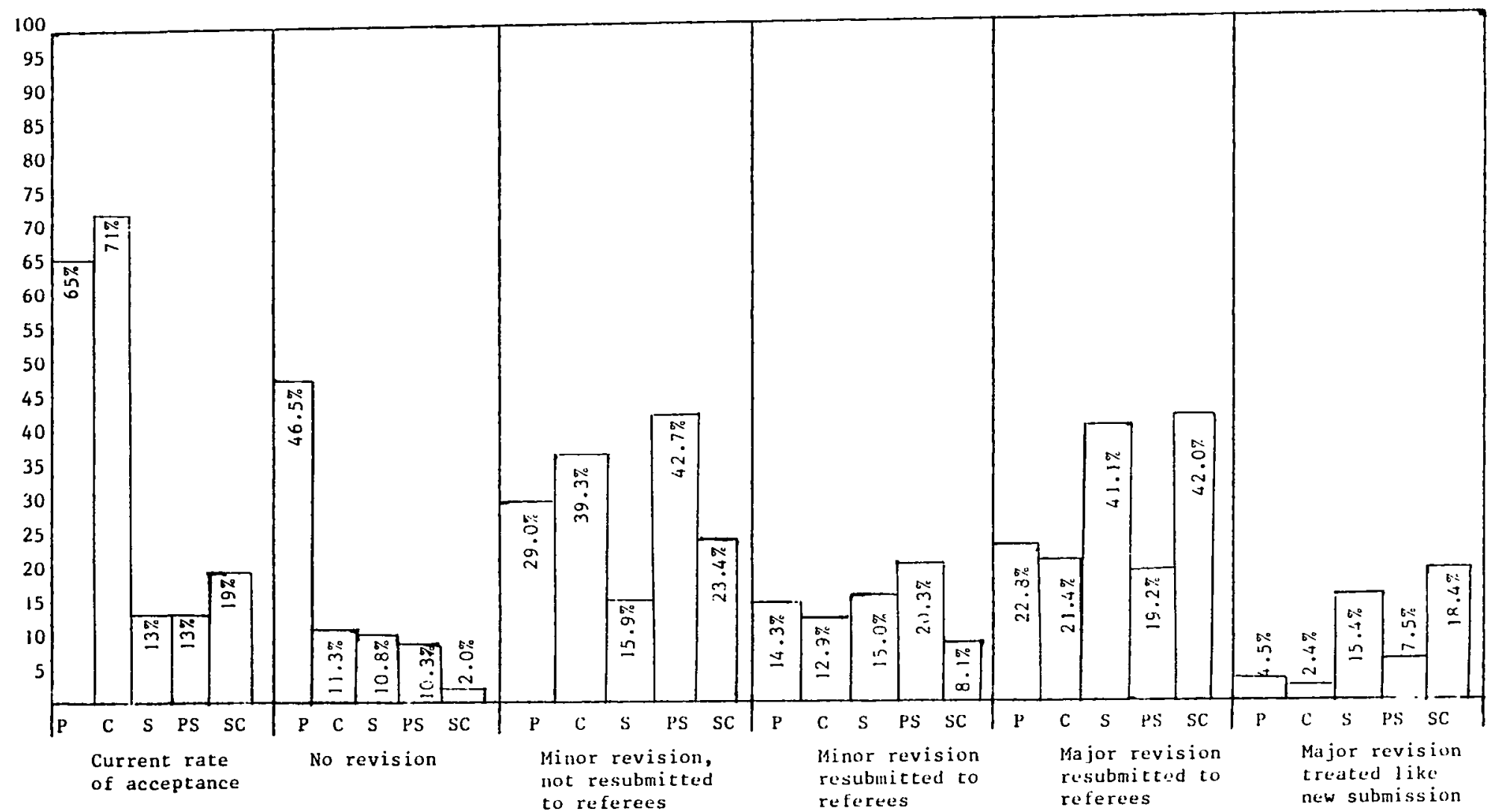

P-Physics** C Chemistry** S=Sociolnny* ra:Politiral Sciencex St-Speech Conmunication

* Data were analyzed usinndescriptive statistics and are not meant to support statistical inference.

**Taken from Beyer 1978, p. 77. 
in the range 08 to $60 \%$. The mode was 0 (see "minor revision", Table II). Similarly, this criteria varied in the other disciplines (see "minor revision", Chart I): Physics at 298 , Chemistry at $39.3 \%$ and Political science at $42.7 \%$. Sociology required the most referee involvement where an average of only 15.98 did not need referee supervision.

As can be seen in Table II, the percentage of speech Communication journal manuscripts requiring minor revision that are resubmitted to referees is fairly small, 8.1\%. Generally, manuscripts submitted to speech Communication journals require major revisions and are resubmitted to referess 428 of the time. Again the range was 08 to $60 \%$, but the mode for this variable was $30 \%$ (see "major revisions-resubmitted", Table II). Also, $18.4 \%$ of Speech Communication manuscripts require major revision and are treated like new submissions.

In examining data concerning patterns of revision across the five disciplines (Chart I), Speech Communication has the lowest proportion of manuscripts requiring no revision, and the greatest percentage of manuscripts requiring major revisions which are either resubmitted to referees (428) or treated like a new submission (18.48). This process of revising and resubmitting to the peer review system indicates additional decision-making procedures involved in accepting and rejecting speech Communication manuscripts. of the other disciplines, Physics had the highest percentage 
of manuscripts requiring no revision (46.5\%) while Chemistry required the lowest percentage of revised manuscripts that are treated like a new submission (2.4\%). Political science journals had the highest percentage of revised manuscripts not resubmitted to referees (42.78), although Chemistry journals were close at 39.3\%. Finally, Sociology journals were most 1 ike Speech Communication in that they required 41.18 of manuscripts to pe revised and resubmitted to referees and 15.48 were revised and treated like an new submission.

The measure of manuscript revision suggesting greater or lesser paradigm development places Speech Communication as the least developed field (of the five examined) on the paradigm development continuum. The rate of acceptance, however, does seem to indicate a willingness to accept and then revise.

\section{The Refereeing Process}

One of the safeguards of the evaluation process is the peer review system. As such, Beyer (1978) maintained that fields with greater paradigm development (Physics and Chemistry) rely more on referees than do fields with less developed paradigms (Sociology and Political science). This group of questions relates to sub-hypothesis 2 (See Chart II). All speech Communication journals assessed in this study stated that at least $70 \%$ of all manuscripts were sent to referees (range, 708 to 1008 ). Four Speech Communication 
journals reported that 1008 were sent to referees, one stated 99.98, one 988 , two at 958 , one at 908 and one at 858 (see " $z$ of manuscripts refereed", Table III). The mean for the discipline was 93.98 . In contrast, as can be seen in Chart II (' of manuscripts refereed'), the mean for Sociology was $86.7 \%$ and Political science $74.3 \%$ while the mean for Physics was 94.68 and for Chemistry it was 99.7\%. Beyer summed up the implications of these statistics for her study in this way:

While the use of referees does not guarantee universalistic assessment, the failure to use referees may increase the impact of the editor's biases and values upon the content of the journal, even though editors may try to be impartial (p. 76).

Based on Beyer's analysis of Physics, Chemistry, Sociology, and Political science (above), the conclusion that the use of referees helps mitigate the biases of editors could be extended to speech Communication. Speech editors could be described as making an effort to be impartial since an average of 93.98 of the time they do use referees in the manuscript selection process.

Data analysis of responses on percentage 의 mannu= scripts not refereed that are rejected was more difficult than the preceding question because respondents in speech Communication (see Table III) recorded percentages that were congruent with the first question, percentage of manuscripts refereed, while the other four gave inconsistent answers. Based on this fact the mean for this variable was computed 
TABLE \|\|

THE REFEREEING PROCESS AND REJECTION RATES IN SPEECH COMMUNICATION JOURNALS*

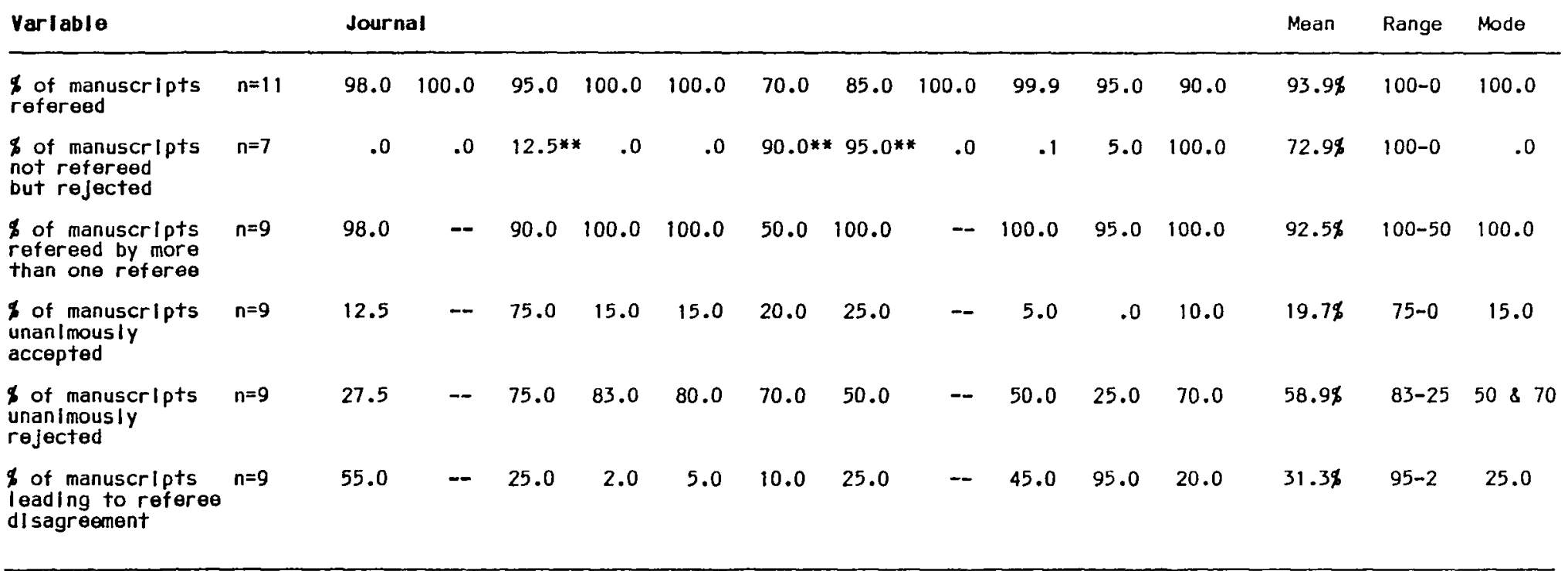

*Data were analyzed using descriptive statistics and are not meant to support statistical inference.

** Inconsistent data. 
CHART II

THE REFERFEING PROCESS ANI) REJECTION RATES FOR FIVE DISCIPLINES

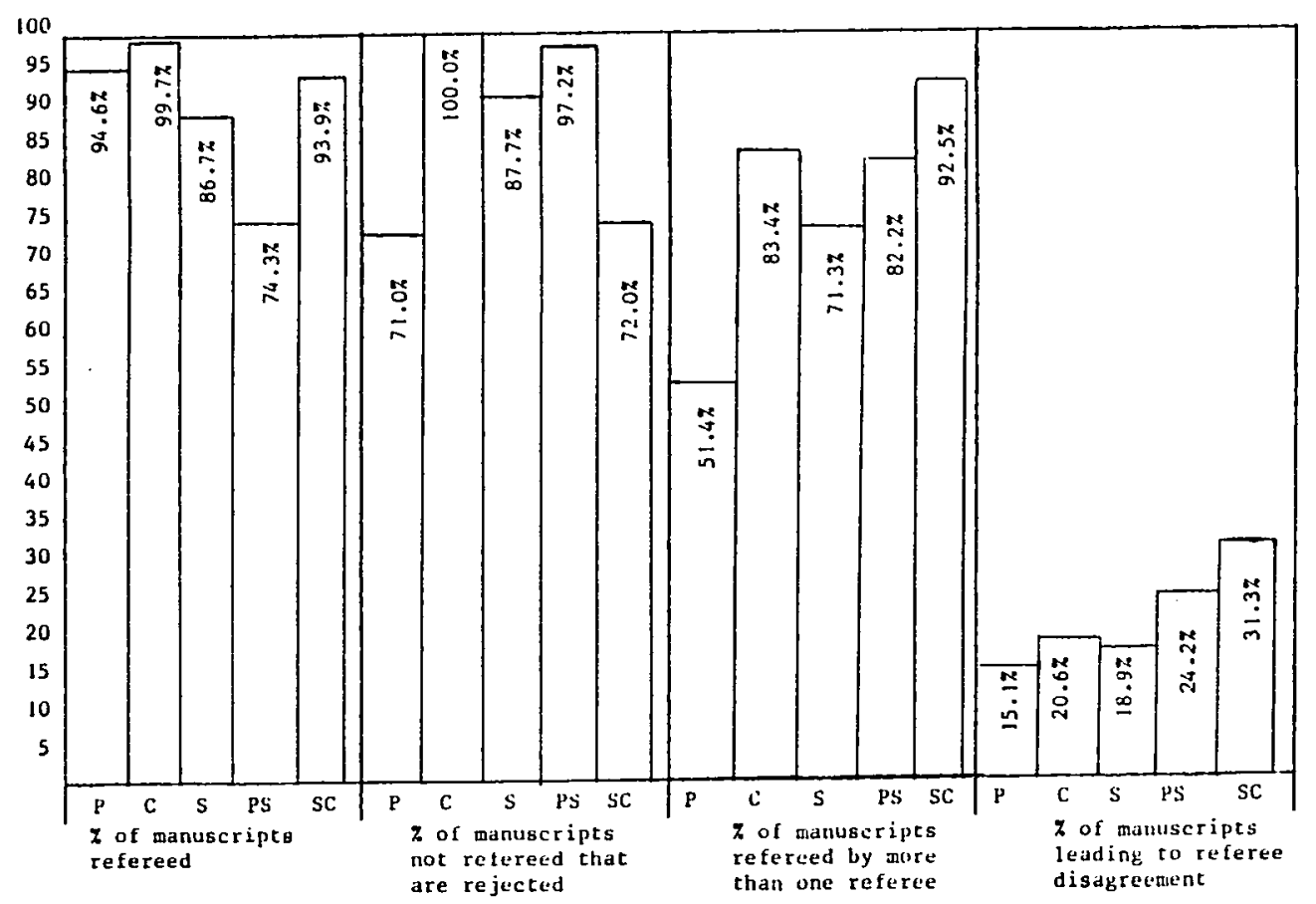

P=Physics** C=Chemistry** S=Sociology** PS=Polltled Sclence** SC-Speesch Communicution

-1)ata mere analyzed using descriptive statistles dind are nut meant to support statistical infercice.

*Taken from Beyer 1978, p. 76. 
with an "n" of 7 , for a mean score of 72.98 .

The next question in this series related to the refereeing process requested the percentage of manuscripts refereed by more than one referee (see Table III). Nine answers were supplied by speech communication journal editors. Five said all, that is, 1008 of the manuscripts, were reviewed by more than one referee. The mean was $92.5 \%$ and the range was $50 \%$ to $100 \%$. In comparing editors in Speech Communication to the other disciplines (see Chart II), Speech Communication editors used at least two referees on a more frequent basis ( $92.5 \%$ ) than did editors of the other four fields. This could account for the fact that the largest proportion recorded for percentage of manuscripts leading to referee disagreement, where the editor could not follow recommendations routinely, was in speech Communication (31.38).

Two additional questions were asked of speech Communication editors that were not part of Beyer's (1978) research (see Table III). Editors were asked, What is the percentage of manuscripts unanimously accepted by referees? of the nine who responded, the data ranged from 0 s to a high of 75\%. The remaining data varied from 58 to $25 \%$. The mean was $19.7 \%$ and the mode was $15 \%$. The second question was: What is the percentage of manuscripts rejected unanimously by referees? The mean of the nine respondents was 58.98 and the mode was 50 and 70. 
Based on these data, it appears that the peer review system greatly influences manuscript publication. To gain more insight into the role of the editor in conjunction with the referee process, an open-ended question (also not in Beyer's study) was asked: "What are the procedures you use for handling referee disagreement?" Ten editors responded. Six explained that the manuscript in question would either go to a third reviewer or the editor himself would act as a third referee. Another editor wrote:

I have never had a manuscript receive three 'accepts' so to that degree, there has been referee disagreement on all manuscripts mailed out. In some cases I send consultants copies of the other consultant critiques. On several occasions I have simply considered one critique as being deviant.

In each of the ten explanations, final decisions for acceptance or rejection were explained as exercised by the editors. The following respondent's answer illustrates an editor's decision-making process:

In the first place, I do not consider that referees 'disagree' when they both suggest revisions, even when one suggests minor revisions and the other suggests major revisions. Early in my editorial tenure, I automatically sent the manuscript to a third reviewer and asked for a 'break the tie' decision. With a present backlog of accepted manuscripts, I can be more 'choosy.' When I have a referee disagreement (defined as 'accept' and 'reject' recommendations) at present, I look at the referee's reasons for rejection. If they are inherent in the study and the referee's judgment is based on sound argument and rationale, I opt for the rejection. If the study is 'salvagable' by major revisions and is worth salvaging because of the potential value of the study, I ask for those revisions under a 'revise and resubmit' decision. The ultimate 'procedure' for handling referee disagree- 
ment must be the judgment of the editor as to the potential worth of the manuscript. And my criterion for ultimate worth is always 'so what?' Does the manuscript contribute significantly to our understanding of human communication?

Relating one of Beyer's hypotheses to the referee process (this study's sub-hypothesis 2) highlights the link of the evaluation process with paradigm development. As Beyer (1978) stated and was adopted in this study as subhypothesis 2 :

Editors of journals in fields with more developed paradigms will report less difficulty in arriving at the decisions of whether to publish manuscripts than editors of journals in fields with less developed paradigms (p. 70$)$.

The data gathered in this study suggest that the peer review system is widely used in the field of speech Communication. Based on the literature, referee involvement in the review process could increase the use of universalistic criteria to judge manuscripts where scholars examining the same manuscript would come to similar evaluative conclusions. Because of their heavy reliance on referees, editors in speech Communication are using more decision-making steps than those editors in Physics or Chemistry. However, this referee-editor relationship has not overwhelmingly hindered time elements in the publication process. This point will be further elaborated in the following paragraphs. Thus, Speech Communication, due to its greater use of refereeing steps, may protect the discipline from editor bias. 


\section{Time Periods for Publication}

For purposes of clarity, in this section of the data analysis, the precise format of the Survey of Editors will not be followed. Combined in the forthcoming paragraphs will be information concerning time periods for publication, general publication information and data about article length and journal content which was gathered from the actual issues of the journals in this investigation. The outside source data was obtained from the journals for 1981. Beyer's study also computed data for Physics, Chemistry, Sociology, and Political science from journal publications during 1973 (see Table V). This study's sub-hypothesis 3 proposed :

Journals in fields with less developed paradigms will have longer time lags between submission and publication than journals in fields with more developed paradigms (Beyer 1978, p. 71).

For those publishing in speech Communication journals, the mean time lag between submission and publication of a typical manuscript was 9.4 months (see Table IV). The longest wait was 14 months and the shortest time was 3.5 months. In this case, speech Communication falls in the middle; the fields having greater paradigm development taking 5.5 (Physics) and 6.2 months (Chemistry) from submission to publication and the lesser developed fields requiring 13.6 (Sociology) and 13.2 months (Political science) (see Table V). In addition, editors in speech communication 
TABLE IV

TIME PERIODS BETWEEN MANUSCRIPT SUBMISSION AND PUBL ICATION IN SPEECH COMMUNICATION JOURNALS*

\begin{tabular}{|c|c|c|c|c|c|c|c|c|c|c|c|c|c|c|c|}
\hline Varlable & & Journ & & & & & & & & & & & Mean & Range & Hode \\
\hline $\begin{array}{l}\text { of months from } \\
\text { submission to } \\
\text { publication }\end{array}$ & $n=11$ & 3.5 & 14.0 & 6.0 & 12.0 & 13.5 & 7.5 & 12.0 & 9.0 & 7.5 & 6.5 & 12.0 & 9.5 & $14-3.5$ & 12.0 \\
\hline $\begin{array}{l}\text { Shortest } \\
\text { Interval to } \\
\text { publication }\end{array}$ & $n=9$ & 2.0 & 3.5 & 3.0 & -- & 3.0 & 3.0 & 3.0 & 3.0 & 6.0 & 5.0 & -- & 3.5 & $6-2$ & 3.0 \\
\hline $\begin{array}{l}\text { of months } \\
\text { between decision } \\
\text { to publish and } \\
\text { actual publication }\end{array}$ & $n=11$ & 3.0 & 13.0 & 4.5 & 10.0 & 10.5 & 4.5 & 3.5 & 9.0 & 5.0 & 5.0 & 4.0 & 6.5 & $13-3$ & 4.5 \\
\hline $\begin{array}{l}\text { of months } \\
\text { required for } \\
\text { publlcation } \\
\text { process } \\
\text { exclusively }\end{array}$ & $n=9$ & 2.0 & 3.0 & 3.0 & -- & 4.0 & 3.0 & 3.0 & 1.0 & -- & 3.0 & 2.0 & 2.7 & $4-1$ & 3.0 \\
\hline
\end{tabular}

*Data were analyzed using descriptive statistics and are nut meant to support statistical infurence. 
TABLE $V$

TIME PERIODS BETWEEN MANUSCRIPT SUBMISSION AND PUBL ICATION IN FIVE DISCIPLINES*

\begin{tabular}{|c|c|c|c|c|c|}
\hline \multirow[b]{2}{*}{ Vorlable } & \multicolumn{5}{|c|}{ Journal Masns } \\
\hline & Physlcs ${ }^{* *}$ & Chemlstry"* & Soclology** & $\begin{array}{l}\text { Pollitical } \\
\text { Sclence* }\end{array}$ & $\begin{array}{c}\text { Speech } \\
\text { Communication }\end{array}$ \\
\hline & $n=7$ & $n=9$ & $n=9$ & $n=6$ & $* * *$ \\
\hline $\begin{array}{l}\text { Number of months between } \\
\text { submission ond publication } \\
\text { of typlcal menuscript }\end{array}$ & 5.5 & 6.2 & 13.6 & 13.2 & $9.4^{b}$ \\
\hline $\begin{array}{l}\text { Shortest Interval to } \\
\text { pubilication }\end{array}$ & 2.0 & 3.6 & 8.3 & 6.8 & $3.5^{\mathrm{a}}$ \\
\hline $\begin{array}{l}\text { Months between decislon } \\
\text { to publish and actual } \\
\text { publication }\end{array}$ & 4.1 & 4.0 & 9.2 & 8.7 & $6.5^{b}$ \\
\hline $\begin{array}{l}\text { Months requilred for } \\
\text { publication process } \\
\text { excluslvely }\end{array}$ & 3.3 & 3.2 & 5.0 & 4.7 & $2.7^{\circ}$ \\
\hline
\end{tabular}

*Data were analyzed using descriptlve statistics and are not meant to support statistlcal Inference

* Taken from Beyer 1978, p.80.

w* " $n$ varled from $n=9^{a}$ to $n=11^{b}$. 
consume the least amount of time of all the disciplines for the publication process, 2.7 months exclusively.

Information related to the publication process in general concerns number of manuscripts submitted annually, tenure of present editor, and tenure of previous editor (see Table VI). In examining the five disciplines, one can see that speech Communication journals on the whole receive fewer manuscripts than the other disciplines. Conjecture as to the field's limited annual output could probably be endless. However, possible reasons for having a smaller number of articles published may be found in what those in Speech Communications do. Goodall and Phillips (1981) explained that:

In Speech Communication, the bulk of the effort is devoted to improving performance skills or teaching general principles applicable to life experience. Consequently, the gap between doers of research and consumers of research is wide (p. 283).

Other possible reasons are that since the discipline is relatively "new", it has yet to establish itself and thus attract authors. Or, it may be that potential authors are reluctant to bother with the type of revisions necessary for most scholarly journal articles (Benson, 1979). Too, possibly a larger number of prospective speech Communication authors are publishing their work in journals of other fields (Bochner, 1977). Whatever the true reasons, there is a clear difference between the number of articles published in speech Communication and the other disciplines. 
TABLE VI

NUMGER OF MANUSCRIPTS SUBMITTED ANMUALLY AND EDITOR TENURE FOR FIVE DISCIPLINES"

\begin{tabular}{|c|c|c|c|c|c|}
\hline \multirow[b]{2}{*}{ Varlable } & \multicolumn{5}{|c|}{ Journal Mans } \\
\hline & Physlcs" & Chemlstry & Soclology & $\begin{array}{l}\text { Polltical } \\
\text { Sclence*: }\end{array}$ & $\begin{array}{c}\text { Speech } \\
\text { Communl cotion }\end{array}$ \\
\hline & $n=7$ & $n=9$ & $n=9$ & $n=6$ & $n=11$ \\
\hline $\begin{array}{l}\text { Number of manuscripts } \\
\text { submitted annually }\end{array}$ & 1358.3 & 1529.3 & 461.7 & 306.0 & 176.6 \\
\hline $\begin{array}{l}\text { Tenure of present } \\
\text { editor }\end{array}$ & 6.0 & 10.6 & 4.1 & 5.3 & 4.0 \\
\hline $\begin{array}{l}\text { Tenure of prevlous } \\
\text { editor }\end{array}$ & 5.0 & 8.3 & 2.6 & 2.5 & 2.1 \\
\hline
\end{tabular}

"Data were analyzed using descriptlve stotistics and are not meant to support statistical inference.

"Taken from Beyer 1978, p. 84. 
Editor tenure has important implications for publishing due to editor influence for a continuous period of years (see Table VII). For instance, Speech Communication editors generally serve three-year terms. Two journals within the discipline, however, have had the same editor for the last ten years. The mean score for present editor tenure in Speech Communication was 4.0 years while Chemistry editors served an average of 10.6 years. Tenure of previous years follow similar patterns, yet their terms in office were less. Previous tenure for Speech Communication editors was 2.2 years, while for Chemistry it was 8.3 years. In comparing both previous and present terms of editorship among identified "lesser" and "greater" paradigmatic fields, Speech Communication is statistically similar to Sociology and Political Science.

As can be seen in Table VIII, within the discipline of Speech Communication, there was great diversity concerning all manuscript length and content variables. The average article length ranged between 9.2 and 25.4 pages, a difference of 16.2 pages. Ten out of the eleven journals publish quarterly while the eleventh publishes on a semiannual basis. Total number of articles published in 1981 varied from a low of 12 to a high of 74 . The total number of pages of articles per volume ranged from 139 to 729; the mean was 355.7 ; and the mode was 337 . Nine of the eleven journals contained pages of advertising, varying from 8 to 
TABLE VII

MUMBER OF MANUSCRIPTS SUBMITTED ANNUALLY AND EDITOR TENURE FOR SPEECH COMANUNICATION JOUPNALS

\begin{tabular}{|c|c|c|c|c|c|c|c|c|c|c|c|c|c|c|c|}
\hline Verlable & & Journe & & & & & & & & & & & Moan & Range & Mode \\
\hline $\begin{array}{l}\text { Number of } \\
\text { monuscrlpts } \\
\text { submitted } \\
\text { annually }\end{array}$ & $n=11$ & 275.0 & 100.0 & 100.0 & 150.0 & 110.0 & 400.0 & 125.0 & 400.0 & 100.0 & 137.5 & 45.0 & $\begin{array}{c}176.6 \\
\text { menuscripts }\end{array}$ & ${ }_{5}^{400-45}$ & 100.0 \\
\hline $\begin{array}{l}\text { Tenure of } \\
\text { present editor }\end{array}$ & $n=10$ & 3.0 & -- & 10.0 & .5 & 3.0 & 10.0 & 3.0 & 3.0 & 3.0 & 3.0 & 1.5 & $\begin{array}{c}4.0 \\
\text { years }\end{array}$ & $10-.5$ & 3.0 \\
\hline $\begin{array}{l}\text { Tenure of } \\
\text { prevlous editor }\end{array}$ & $n=10$ & 3.0 & - & .0 & 3.0 & 3.0 & .0 & 3.0 & 3.0 & 3.0 & 3.0 & .5 & $\begin{array}{l}2.2 \\
\text { years }\end{array}$ & $74-12$ & 3.0 \\
\hline
\end{tabular}

"Dato were analyzed using descriptive statistics and are not meant to support statistical inference. 
TABLE VIII

ARTICLE LENGTH AND JOUPNAL CONTENT FOR SPEECH COMNUNICATION JOURNALS DURING 198I"O

\begin{tabular}{|c|c|c|c|c|c|c|c|c|c|c|c|c|c|c|c|}
\hline Varlable & & Journe & & & & & & & & & & & Maan & Range & Mode \\
\hline $\begin{array}{l}\text { Average ortlcle } \\
\text { length }\end{array}$ & $n=11$ & 11.2 & 14.7 & 25.4 & 14.5 & 12.3 & 9.9 & 9.5 & 9.2 & 17.7 & 13.3 & 11.6 & $\begin{array}{l}13.6 \\
\text { pages }\end{array}$ & $25.4-9.2$ & 9 \\
\hline $\begin{array}{l}\text { Number of Issues } \\
\text { In } 1981\end{array}$ & $n=11$ & 4.0 & 4.0 & 4.0 & 4.0 & 4.0 & 4.0 & 4.0 & 4.0 & 4.0 & 4.0 & 2.0 & $\begin{array}{c}3.8 \\
\text { Issues }\end{array}$ & $4-2$ & 4 \\
\hline $\begin{array}{l}\text { Total number of } \\
\text { articles published }\end{array}$ & $n=11$ & 22.0 & 21.0 & 19.0 & 26.0 & 29.0 & 74.0 & 29.0 & 33.0 & 19.0 & 27.0 & 12.0 & $\begin{array}{l}28.3 \\
\text { articles }\end{array}$ & $74-12$ & 19829 \\
\hline $\begin{array}{l}\text { Total number of } \\
\text { peges of orticles }\end{array}$ & $n=11$ & 246.0 & 309.0 & 482.0 & 378.0 & 356.0 & 729.0 & 275.0 & 302.0 & 337.0 & 360.0 & 139.0 & $\begin{array}{l}355.7 \\
\text { pages }\end{array}$ & $729-139$ & 337 \\
\hline $\begin{array}{l}\text { Total number of } \\
\text { pages of } \\
\text { advertising }\end{array}$ & $n=11$ & 35.0 & 50.0 & 8.0 & 20.0 & 10.0 & 15.0 & 13.0 & 15.0 & .0 & 36.0 & .0 & $\begin{array}{l}18.4 \\
\text { pages }\end{array}$ & $50-0$ & 1580 \\
\hline $\begin{array}{l}\text { Total number of } \\
\text { pages of book } \\
\text { revlews }\end{array}$ & $n=11$ & 36.0 & 124.0 & 24.0 & .0 & .0 & 116.0 & .0 & .0 & .0 & 45.0 & 12.0 & $\begin{array}{l}32.5 \\
\text { pages }\end{array}$ & $124-0$ & 0 \\
\hline $\begin{array}{l}\text { Averago } \\
\text { circulation }\end{array}$ & $n=11$ & 5,000 & 5,981 & 1,100 & 2,500 & 2,800 & 6,500 & 2,200 & 2,700 & 3,700 & 2,500 & 300 & $\begin{array}{l}3207.4 \\
\text { clrculation }\end{array}$ & $n^{6500-300}$ & 2,500 \\
\hline
\end{tabular}

"Date were analyzed using descriptive statistics and are not meant to support statistical inference.

abate for this table were gathered from the journals themselves. 
50 pages. Fewer journals, six in total, include book reviews, where the total number of pages ranged from 0 to 124 pages.

In relation to the other disciplines, the overall mean for number of pages of book reviews in speech Communication more closely resembles the physical science journals than the social science journals. In this case, speech Communication's mean is 32.5 pages while Physics is 10 , Chemistry is 14.3, Sociology is 97.6 and Political science is 162.5 (see Table IX). Based on these statistics, the role of books within Speech Communication is difficult to determine. Beyer stated of the social sciences that:

Beyer and Snipper (1974) found books to be much more frequent publication outlets for social scientists than for physical scientists in U. S. universities. Scientists in fields with less developed paradigms probably write more books because they need more space to explicate their findings and document them while also considering rival theories, methods, etc. specialized book review journals are being founded, and this may eventually provide more space for articles within present social science journals (p. 80).

Since space availability is at a premium in the journal publication enterprise, sub-hypothesis 4 stated:

Articles appearing in journals in fields with developed paradigms will be shorter than articles appearing in journals in fields with less developed paradigms (Beyer 1978, p. 70).

The mean statistics shown in Table IX would seem to indicate that Speech Communication appears to have the fewest issues (3.8 annually), the least number of articles published $(28.3$ 
annually), and the smallest number of pages of articles (355.7 annually).

In an effort to gain a better understanding of space availability in the various journals, a "scarcity ration is needed. Scarcity refers to the "real" amount of space in a journal available to authors. Beyer (1978) described a procedure for arriving at such a ratio.

Following Hargens (1975:20-1), ratios were computed in which the average circulation was divided by the average number of manuscripts published yearly by journals in this sample within each of the four fields; this measure is intended to be a rough indicator of scarcity of space within each field. Results gave ratios of 7.6 for physics, 9.8 for chemistry, 114.8 for sociology, and 195.7 for political science, documenting that a space scarcity is inversely related to the level of paradigm development originally attributed to these fields (Lodahl and Gordon, 1972) (Beyer, 1978, p. 79).

Using this formula, then, speech Communication's scarcity ratio was 113.4. Thus, speech Communication journals had slightly more space than sociology (114.8) and much more than Political science (195.7), but much less than Physics (7.6) and Chemistry (9.8). This particular datum places Speech Communication in the lesser paradigm development domain. While speech Communication journal articles are typically long (13.6 pages), the scarcity ratio (133.4) and book review pages (32.5) indicate that it is questionable whether Beyer's conclusion regarding the importance of books in the social sciences can be extended to speech Communication. There are insufficient data to clearly determine whether the field of speech Communication emphasizes books 
TABLE IX

MEANS OF ARTICLE LENGTH AND JOUPNAL CONTENT FOR FIVE DISCIPL INES"

Journal mans

\begin{tabular}{|c|c|c|c|c|c|}
\hline Verlable & Physles * & Chenistry ** & Soclology" & $\begin{array}{l}\text { Pollticel } \\
\text { Sclence }\end{array}$ & $\begin{array}{c}\text { Speech } \\
\text { Communl cation }\end{array}$ \\
\hline Average article length & 12.6 & 5.3 & 14.9 & 14.6 & 13.6 \\
\hline $\begin{array}{l}\text { Number of } b_{1573^{a}-1981^{b}} \\
\end{array}$ & $28.0^{\circ}$ & $22.2^{\circ}$ & $5.1^{\circ}$ & $4.7^{a}$ & $3.8^{b}$ \\
\hline $\begin{array}{l}\text { Total number of articles } \\
\text { published }\end{array}$ & 700.7 & $1,097.6$ & 59.9 & 45.5 & 28.3 \\
\hline Pages of articles & $3,999.7$ & $4,688.6$ & 679.1 & 610.3 & 355.7 \\
\hline Pages of advertising & .0 & 137.3 & 54.8 & 65.8 & 18.4 \\
\hline Peges of book revlews & 10.0 & 14.3 & 97.6 & 162.5 & 32.4 \\
\hline Scarclty ratlo & 7.6 & 9.8 & 114.8 & 195.7 & 113.4 \\
\hline
\end{tabular}

"Dote were analyzed using descrlptive stotistlcs ond are not meant to support statlstical inference.

* Taken from Beyer 1978, p. 78. 
less or more than the social science disciplines. One could speculate that this is due to their preparadigmatic phase or, possibly, because they are maturing as a discipline in a different manner than "paradigm" would dictate. The question is important and one that deserves future research.

\section{Evaluative Criteria}

This segment of the survey was originally developed by Chase (1970) and later adopted by Beyer (1978). Chase's study asked scientists rather than editors to rank evaluative criteria as to its importance in judging scientific publications. For the present investigation, evaluative criteria included: originality, logical rigor, mathematical/statistical rigor, compatibility with generally accepted disciplinary ethics, clarity and conciseness of writing style, relevance to current areas of reseacch, theoretical significance, positive findings, negative results, replicability and applicability to practical or applied problems (see Table $x, p .85$ ).

Editors were asked to rank the importance of these criteria where (1) = not at all, (2) = somewhat important, (3) = very important but not essential, and (4) = essential. To speech Communication editors, logical riger, compatibility with generally accepted disciplinary ethics, and conciseness of writing style were ranked highest at $3.7,3.8$ and 3.6 respectively. In contrast to the rest of the criteria, only eight out of eleven respondents supplied an 
answer for compatibility with generally accepted disciplinary ethics. In those cases of non-response on this item, several editors asked what the "criterion" was. The variable of negative results was added to the Evaluative Criteria section of the survey of Edjtors in this study not included in Beyer's 1978 study) and was considered the least necessary of all the listed standards with a mean score of 1.9. One editor commented on this criterion: "We'd consider a manuscript where expectations weren't confirmed but those must be interpreted meaningfully." The other ranked criteria ranged from a high of 3.5 to a low of 2.3 (see Table X).

In comparison to the other four disciplines, Chemistry editors were most interested in replicability, (mean score was 4.0) while speech Communication editors ranked it as somewhat important (2.5) (see Table XI). To Physics editors, the most important criterion was originality (3.3). Sociology and Political science editors ranked logical riger as most important at 3.3 and 3.4 respectively. Editors in Sociology, Physics, and Chemistry scored applicability to practical or applied problems as the least important criterion. Finally, Political science editors rated positive findings as not at all important (1.4). Other criteria do not vary dramatically (see Table XI). Thus, logical rigor appeared to be considered the most consistently relevant criterion across the disciplines. 
TABLE $X$

EVALUATIVE CRITERIA OF JOURNALS IN SPEECH COMMUNICATION"

\begin{tabular}{|c|c|c|c|c|c|c|c|c|c|c|c|c|c|c|}
\hline Verlable & Journ & & & & & & & & & & & Masn & Range & Mode \\
\hline Original Ity & 2.5 & 4 & 3 & 2 & 3 & 4 & 3 & 4 & 3 & 2 & 3 & 3.0 & $4-2$ & 3 \\
\hline Logical rigor & 4 & 4 & 4 & 4 & 3 & 4 & 4 & 3 & 4 & 3 & 4 & 3.7 & $4-3$ & 4 \\
\hline $\begin{array}{l}\text { MathematIcal/statl stical } \\
\text { rigor }\end{array}$ & 4 & 4 & 3 & 3 & 4 & 3 & 4 & 2 & 4 & 3 & 4 & 3.5 & $4-2$ & 4 \\
\hline Disclpilnary ethles & 4 & 4 & 3 & 4 & 4 & 4 & 4 & $?$ & $?$ & 3 & $?$ & 3.8 & $4-3$ & 4 \\
\hline Conclse writling style & 4 & 4 & 2 & 4 & 4 & 3 & 4 & 4 & 3 & 4 & 4 & 3.6 & $4-2$ & 4 \\
\hline $\begin{array}{l}\text { Relevance to current } \\
\text { areas of research }\end{array}$ & 2 & 4 & 3 & 3 & 4 & 3 & 4 & 2 & 2 & 3 & 3 & 3.0 & $4-2$ & 3 \\
\hline Theoretlcal signiflcance & 1.5 & 4 & 3 & 4 & 4 & 4 & 3.5 & 2 & 4 & 2 & 3 & 3.2 & $4-1.5$ & 4 \\
\hline Positive fIndings & 1 & 4 & 2 & 4 & 2 & 3 & 2 & 1 & 1 & 2 & 3 & 2.3 & $4-1$ & 2 \\
\hline Negotlive results & 1 & 4 & 2 & 3 & 2 & 1 & 2 & 1 & 1 & 2 & 2 & 1.9 & $4-1$ & 2 \\
\hline RepII cab IIIty & 3 & 4 & 3 & 2 & 2 & 3 & 3 & 1 & 2 & 3 & 2 & 2.5 & $4-1$ & 3 \\
\hline Coverage of IIterature & 2 & 4 & 2 & 3 & 4 & 3 & 4 & 3 & 3 & 3 & 4 & 3.2 & $4-2$ & 3 \\
\hline App I I cab IIIty & 4 & 4 & 1 & 1 & 3 & 2 & 2.5 & 3 & 2 & 2 & 3.5 & 2.5 & $4-1$ & 2 \\
\hline
\end{tabular}

I=not at all Important 2=somewhat Important 3every Important $4=05 s e n t \mid a l$

"Data were analyzed using descriptive statistics and are not meant to support statistical inference. 
TABLE XI

EVALUATIVE CRITERIA OF JOURNALS IN FIVE DISCIPLINES*

\begin{tabular}{|c|c|c|c|c|c|}
\hline \multirow[b]{2}{*}{ Varlable } & \multicolumn{5}{|c|}{ Journal Mans } \\
\hline & Physlcs"* & Chemistry " & Soclology" & $\begin{array}{l}\text { Polltical } \\
\text { Sclence** }\end{array}$ & $\begin{array}{c}\text { Speech } \\
\text { Communlcation }\end{array}$ \\
\hline OrIginallty & 3.3 & 3.2 & 3.2 & 3.0 & 3.0 \\
\hline Loglcal rigor & 2.9 & 3.6 & 3.3 & 3.4 & 3.7 \\
\hline $\begin{array}{l}\text { Mathematical/statistical } \\
\text { rigor }\end{array}$ & 2.7 & 3.4 & 2.6 & 3.2 & 3.5 \\
\hline Conclse wrlting style & 3.0 & 2.9 & 3.2 & 3.2 & 3.6 \\
\hline Theoretlcal signiflcance & 2.0 & 2.3 & 3.2 & 3.2 & 3.2 \\
\hline Posltive findings & 1.4 & 2.3 & 1.8 & 1.6 & 2.3 \\
\hline $\begin{array}{l}\text { Relevance to current } \\
\text { areas of research }\end{array}$ & 3.0 & 2.9 & 3.0 & 2.8 & 3.0 \\
\hline Rep I Icabllity & 2.3 & 4.0 & 2.8 & 2.4 & 2.5 \\
\hline Coverage of Ilterature & 2.4 & 3.4 & 2.5 & 2.2 & 3.2 \\
\hline Appl IcabllIIty & 1.0 & 1.1 & 1.6 & 2.2 & 2.5 \\
\hline
\end{tabular}

Dota vere analyzed using descriptive statistlcs and are not meant to support statistical Inference.

"Taken from Beyer 1978, p. 78. 


\section{Editor Expectations}

Turning now to a more specific internal review of Speech Communication, the final segment of analysis for Part A will examine three open-ended questions concerning editor expectations of their editorships. The first question asked: What was your original intention for the direction and focus of your journal that you wished to display upon assuming your editorship? Two general sentiments were inferred from the data. The first was that the majority of editors wanted their journals to be vehicles of quality scholarship. This view was expressed in terms such as "the best possible scholarship," "high quality manuscripts," "highest standards," and "well-edited." The second major message communicated through the data referred to journals as the "embodiment" of diverse subject matter. This was stated as "broad in its interests," "addressing a spectrum of concerns," "eclectic," "pluralism in regard to assumptions and methods of research," "no favoritism of theoretical orientation or research," and as wanting a "good sampling from various corners of the field."

other random intentions declared by editors were "to advance the field," "increase subscriptions," "be responsive to readership," "publish more research," and "I wanted articles of manageable length so we could keep the maximum number of people from perishing."

These two sentiments exemplify the general feeling 
derived from the literature review. The literature conveyed a picture of speech Communication as broad-based le.g., Ruben and Wiemann, 1979; Bochner, 1977; etc.) where pluralism and diversity are the most commonly used descriptions of the field. That is, it appears that there are conflicting paradigms within the field and that editors want their journals to represent as many of them as possible (cf. Bochner, 1977; Rossiter, 1977). Too, while there is clearly diversity of perspective within the field, there also appears to be general agreement among these editors that improving the quality of scholarship within the discipline is an important function of their journals. However, as was noted in the literature review, diversity of perspective may, in fact, work against the general establishment of "agreed-upon standards" of scholarship for the field.

The next question asked editors: What obstacles, if any, have you encountered in the realization of the above? Four editors said that they had not encountered any obstacles while the remaining seven explained a variety of interfering elements. One editor explained that his high hopes for diversity were too broad and therefore debilitating. Two other editors cited preconceived notions of their journals by prospective article authors as a self-selecting process preempting possible article submission:

The 'image' of the journal and the editor's policy relative to that journal are often not in congruence. Unfortunately, the 'image' cannot be changed 
if the readership's image of that journal results in perpetuating that image through self-selection of submissions. The self-fulfilling prophecy in operation!!

The second editor explained:

Regional journals are not usually the first choice of prospective contributions. Hence, the chances of receiving a high percentage of the best scholarship in the field are reduced.

Additional comments made were: "few papers meet the high standards of my referees," and another editor cited a problem with "building a reliable pool of referees." Obstacles to fulfilling expectations thus included problems with diversity, regional versus national journals, and complications generated by the peer review system.

The last question dealing with editor expectations was posed: Can you identify any changes or modifications in your original intent? Five editors answered "no." The rest of the editors explained in a variety of ways that they are working as best as they know how and are trying to realize their stated goals. One respondent offered this strategy for accomplishing his objectives:

I have discovered that focused submissions are usually of higher quality than random submissions. Therefore, I have declared several special issues of topical interest such as 'women,' 'state of the art in research,' 'effects of technology,' etc. and have issued calls for original papers.

\section{Conclusions}

With regard to hypothesis 2 and four sub-hypotheses tested in Part A of the survey of Editors questionnaire, the 
data suggest that the field of speech Communication has lesser paradigm development than the disciplines it was compared to. This is evidenced by the fact that speech Communication had the lowest percentage of manuscripts of all disciplines examined accepted without revision, the highest percentage of manuscripts requiring major revision and resubmitted to referees, and the greatest percentage of manuscripts requiring major revision and treated like as new submission (see chart I). The only equivocal finding involved the variable percentage of manuscripts reguiring minor revision with no resubmission to referees. These findings indicate that speech Communication is still clearly identified with the lesser developed paradigm camp. Subhypothesis 1 is therefore affirmed.

Lesser developed paradigm status within speech Communication is evidenced in the following variables: highest percentage of manuscripts refereed by more than one referee, the highest percentage of manuscripts leading to referee disagreement, and the third highest percentage ef manu= scripts not refereed but are rejected (see Chart II). From these data it was concluded that speech Communication had a larger number of steps involved in the refereeing process (testing sub-hypothesis 2) and therefore, lesser paradigm development was indicated.

The variable of percentage of manuscripts refereed did not clearly discriminate between the disciplines in that the 
percentage ranged from 74.3 to 99.7 . While there is a significant difference between 74.3 and 99.7 ( $p<25$; Beyer $p$. 76), speech Communication averaged 93.98. Thus, it is not different than the rest of the disciplines because it appears that all disciplines utilize the referee peer review system in most cases. How this relates to paradigm development is not clear.

While Beyer hypothesized that longer time lags between submission and publication will occur in fields with lesser developed paradigms (sub-hypothesis 3), data from this study show that Speech Communication falls in between the identified greater and lesser developed disciplines (Physics/Chemistry vs. Sociology/Political science) on all variables testing this hypothesis (see Table V). Thus, these data can be interpreted as showing that speech Communication has greater paradigm development that the social sciences but lesser paradigm development than the physical sciences.

Beyer posited that articles appearing in less developed paradigm journals will be longer than articles appearing in greater paradigm-developed journals (sub-hypothesis 4). Again the data are inconclusive (see Table IX). Average article length for speech Communication closely resembled the social sciences (13.6 pages). While Physics had a mean score of 12.6 pages. Beyer noted that one journal skewed her sample and she computed a truer score by omitting the extreme journal. Her revised mean was 9.2. Thus, the 
greatest difference was between Chemistry and the social science journals and Speech Communication. No clear conclusion for this variable can be drawn.

Based on the above data and the previous analysis in the results and discussion section, hypothesis two is accepted. Due to the criteria of this study, Speech Communication can be considered a lesser developed discipline in that more manuscripts are rejected in journals in speech Communication than in those of Chemistry or Physics. With regard to editor expectations of their own impact on improving their journals, their responses seem to indicate a desire to facilitate better scholarship within the field and an interest in keeping the discipline broad-based. Having assessed the data from Part $A$ of the survey of Editors, the following is a discussion of the data generated by part $B$ of the questionnaire.

\section{PART B}

The first hypothesis of this research project was explored using Part B of the Survey of Editors questionnaire (see Appendix E). The hypothesis questions: If speech Communication is at the stage of preparadigmatic development, then speech Communication journal editors will identify more than one paradigm operating within the discipline. Editors were asked to respond to several open-ended questions (the actual number of questions answered by editors 
varied due to prescribed response patterns (see Table I, Chapter II). Responses were then content-analyzed according to content categories. Results of this analysis are discussed in the following paragraphs.

\section{Question 1}

What is your assessment of paradigm development within the field of speech Communication as reflected in your journal? Do you think we have any paradigms? Yes or No? Preceding this question was Rossiter's (1977) definition of paradigm (see p. 30) so that editors would have a common way of interpreting the basis of the remaining questions in the survey. The responses were highly related to the conclusions of the Literature Review (see Chapter I). Five editors simply said "no," there are no paradigms within the discipline, and four editors explicitly said "yes." This even "split" in responses was complemented by two volunteer explanations. An additional editor voted "no" (now "no"=6, "yes" 4 ) and he qualified his "no" with the statement "at least none for which there is universal support within the discipline," thus negating his "no" (score now: "no"=5, "yes"=4). Another editor gave an unequivocal "yes" and "no" (this response was equalized and therefore the score remained 5 to 4 , with one undecided and one negated). The "undecided" editor wrote "we have shadows of paradigms." 
Question 2

Former journal editor Felix Berardo of the Journal of Harriage and the ramily contends that the formula of a successful author is a quality manuscript based on research grounded in an established paradigm" (1981, p. 771). Do paradigms influence your editorial decisions and practices? If yes, in what ways? Eight editors responded to question two--four more than were expected based on answering "yes" to guestion one (see Table I, p. 49, Projected Patterns of Response to Part B, Chapter II). While the editors did not follow the questionnaire directions for response patterns, none supplied conflicting responses. Of the four who said "yes" to question one three said "yes" to question two and one said "no" to question two. Three editors checked "yes" to guestion two and provided explanations while five answered "no" to guestion two with one editor explaining why he stated "no". Interestingly enough, the "no" explication echoed the conclusions of a "yes" respondent. The "no" answer stated:

I take issue with some of the points used by Rossiter in his definition of 'paradigm.' I take even greater issue with Berardo's statement because of the way he defined and emphasized the concept of 'established' paradigm...Paradigms are created by modifications in research practices and publications in reputable journals of quality research. When the editor lends credence to paradigms--not on the basis of the quality of that research, but on the basis of its relevance to established practices--the criterion of 'quality' is given less credibility. Which paradigm guides the research enterprise, to me, seems of far less significance than whether the research is any good. One can write in an 'estab- 
lished' paradigm and do good research as well as bad research. Another can write in an 'unestablished' paradigm and do good research as well as bad

research. How, then, can the choice of a paradigm influence editorial decisions and practices?

In this same vein, a "yes" to question one and "yes" to guestion twe response was:

If the article is based upon quantitative research that paradigm must be followed rigorously; similarly for historical/critical research, linguistic research, etc....An article which does not clearly, accurately, appropriately do what it sets out to do should be rejected for its design or for its method. Practicum reports should be clearly and fully explained, and should be transferable to other classroom settings.

Both of these responses illustrate a conceptualization of paradigm in which the demands of good research outweigh the adherence to a paradigm. This could be interpreted to mean that paradigm is less influential than the standards of scientific research. For one of these editors it would seem that paradigm potentially limits the scope of "good" research. While both editors interpret the use of paradigm differently, both believe that the standards of good research are more important than paradigm in their editorial decisions.

The following quote (respondent answered "yes" to question one, "yes" to question two) illustrates that this editor sees paradigm as coloring much good research in that too strict an adherence to paradigm negatively influences the scholar's juagment and results in low receptivity to "other points of view." This editor sees paradigm as 
strongly influencing his decisions in that ardent commitments to a paradigm are rejected outright:

Paradigms are often licenses for bigotry. People locked into paradigms are often intolerant of opposing points of view. I tend to reject articles that appear "religious" in nature and do not leave ends open for criticism and objection.

A third "yes" ("yes" response is clearly acknowledging that paradigms existing within the field influence his decisionmaking) indicates paradigm influence extends to the decision-making process of his editorial consultants. He stated "Yes,"

To the degree that within the individual subdisciplines such paradigms exist and are recognized by the editorial consultants.

Thus three editors who acknowledged the existence of paradigms ("yes" to question one) said that paradigms do influence editorial decisions. One editor who acknowledged paradigms said they do not influence his decisions. Five editors who did not believe there were speech Communication paradigms answered "no" to this question. This "no" response is not inconsistent with their position in that, if there are no paradigms, how can they influence editorial decisions? Four of the eleven editors see paradigm as influencing the field. However, two of the four interpret this influence as potentially detrimental in its effects. Only one of the eleven editors clearly posits a positive effect from paradigm influence within the discipline. 
Question 3

If you agree that there are operative paradigms as indicated in question one would you label each one and describe its philosophical underpinnings? That is, what makes the paradigm you describe distinctive? Five editors supplied information for this question: the four who answered question one "yes" and the "undecided" respondent. Two (of the five) editors succinctly described three paradigms within the field: Rhetoric, Behaviorism and Constructivism. An examination of the original Content Categories presented in Chapter II suggest that the three paradigms identified can be located in one of two categories, where Rhetoric and Constructivism are placed in the "humanistic" sphere and Behaviorism in the "behavioristic" domain. The "paradigm" of Rhetoric was placed in the humanistic content category because it is clearly part of the humanistic delineation of paradigm described by Tucker, et al. (1981) which helped form the basis for this investigation. Similarly, Constructivism can be placed within the humanistic category because constructivism "sees persons as approaching the world through processes of interpretation...behavior is organized through the application of interpretive schemes as well as strategies that translate intentions into behavioral displays" (Delia, O'Keefe and O'Keefe, 1982). This definition of human intentionality closely resembles Bowers' (1982) discussion of "action school" which adds an integral 
component to the humanistic content category of this study (see Chapter II, Content Categories).

A third editor stated that the diversity of the field launches paradigm into an identification of sub-disciplines which he did not name. While a fourth, using the common dichotomy of behaviorism and humanism, identified a "variety" of paradigms stemming from the larger two:

'Good Terms' for current paradigms can be as broad as 'Quantitative Research,' or 'Humanistic Research,' or more precise and more limited, as in such cases as 'dramatism,' 'metaphor,' 'hermeneutics,' 'form and genre,' 'discourse analysis,' or 'semiotics'...They also are oriented to particular 'fields of argument'--thus various paradigms can be brought to bear in the consideration of a single problem (as in the various approaches to the study of classroom communication: e.g., interpersonal communication studies; linguistic studies; symbolic communication studies; studies based on power analysis, etc.).

The fifth editor responded by explaining "labels" that he created in an attempt to describe paradigms in speech Communication: Mechanism, Psychologism, Interactionism and Pragmatism. Of these four names, two could be pigeonholed as behavioristic (mechanism and psychologism) and humanistic (interactionism):

I definitely believe that there are operative paradigms in communication...Mechanism, Psychologism, Interactionism and Pragmatism. Although I would expand the perspective/paradigm of pragmatism to include much more of the research which focuses on the actions/events/behaviors of communicators as the principal components of communication inquiry (and variables of communication) to include the research on conversation analysis (some of the research on discourse analysis), the organizational culture research, etc. I also think that paradigms are identifiable not by research methods employed, but by 
locus of the phenomena assumptions about the phenomena, exemplars of research practices and products. For this reason (among others), I dislike Rossiter's definition and discussion of paradigms which tends to identify them in terms of methods and techniques (the form rather than the substance/form of communication inquiry).

Mechanism and psychologism were placed in the "behavioristic" category because they are implied in the basic characteristics and assumptions identified in the Content Category discussion of behaviorism (see Chapter II, Content Categories). Interactionism, while not defined, was interpreted to mean a hermeneutic approach to communication and therefore categorized as "humanistic". Pragmatism, although not really defined, could be put into the third "other" content category. Fisher (1982) remarked:

To think of communication as prompted by intentions, motives, cognitions, and so on, is to employ a different conceptual basis. The pragmatic perspective provides its own conceptual basis and contains no residue, even implicitly, of another independent conceptual system (p. 198).

Only time and interest will tell if this "other" perspective will be embraced as an organizing principle for theory and research within the discipline.

Based on a review of the literature, content categories for paradigms within the field of speech Communication were developed along the lines of Tucker, et al. (1981) resulting in two major paradigm domains: "behavioristic" and "humanistic," and one possible "other" paradigm, pragmatism. Of the responses to question three, two answers were outside of the two previously delineated content cate- 
gories: one, the response that there was too much "diversity" in the field to identify paradigms, and two, the response concerning a pragmatic paradigm. This leads to the conclusion that even though the labels may be different, the philosophical underpinnings of these perspectives are easily identified by these editors. It is clear that based on the responses that identified paradigms, all fit within this study's previously constructed content categories. This leads to the affirmation of a preparadigmatic stage of development for the field of speech Communication.

Whether, or to what degree, the two or three "paradigms" adequately describe the discipline cannot be concluded from the data generated by this study. The fact that the perspectives fit into the a priori categories developed from the literature only testifies to their existence. While five of the eleven editors did not think speech Communication had any paradigms, it cannot be concluded that they do not operate under some perspective. These negative responses may be explained by the fact that the concept of paradigm as a label does not in their opinion adequately describe the phenomena or the discipline. As evidenced in the Literature Review, paradigm definitions abound and there is little consensus as to its precise meaning or actual existence in any field outside of the physical and natural sciences. Thus, further research is called for regarding 
the direction of the field of speech Communication and the applicability of paradigm within it.

\section{Question 4}

If you believe there are no paradigms within the field of Speech Communication, could you briefly outline your reasons for that conclusion? As was projected as a result of answers to question one six of the eleven editors responded to this question (those answering "no" to guestion one were directed to answer question four). However, one response was so vague that it could not be adequately interpreted. Generally, the remaining five editors described the field as too divergent for a paradigm to exist (e.g., aparadigmatic). But, when their comments were examined, this finding was not supported. The following quotes are their comments :

We are highly derivative; we borrow from related, better established fields (psych, criticism, philosophy) which have their own paradigms or at least are in more advanced 'pre-paradigmatic' state.

This response can be interpreted to mean that while speech Communication doesn't have paradigms, the fields it borrows from do. This raises the question, If you "borrow" paradigms does that indicate the field is aparadigmatic? In addition, this respondent identified speech Communication as being "only" somewhat less advanced in its preparadigmatic development than the disciplines it borrows from. The conclusion to be drawn from this answer is that Speech Communi- 
cation is not aparadigmatic. One editor stated:

We're so broad and eclectic - the genuinely great ideas encompassing and transforming a field are absent for us - we have no equivalent of the germ theory of medicine, the psychodynamic view of personality, Copernicus' laws of the rotation of orbit of celestial bodies, etc. We do good work - perhaps within a narrow focus. If you're willing to call that focus a paradigm - ok. I don't see what that gets you.

While he says there is no "germ theory" for Speech Communication, he does not describe speech Communication as not having paradigms. The message to be derived from this response is that "paradigm" as a concept is troublesome to this editor. Another editor commented:

I go back to the problem of diversity within the field. The folks in Rhetoric and Public Address have little in common with some of the folks in theatre, oral interpretation, applied communication, cross-cultural communication and the like.

This response also does not describe Speech Communication as aparadigmatic. It could be inferred from this answer that while there may be no overarching paradigm for the field, the sub-disciplines are operating under divergent paradigms. Thus, this response is interpreted to say that speech Communication is preparadigmatic.

In the following answer, an editor made a case for aparadigmatic status within speech Communication. He enumerated:

(1) The foci of communication are not well defined

(2) The set of concepts central to the development of a paradigm have yet to be identified and agreed upon 
(3) Trendiness of scholarly norm in the field

(4) The representatives of the field are not agreed that speech Communication is a science.

Finally, one editor supplied this example of a different interpretation of paradigm where paradigm is located in the individual scholar and not represented by the field of scholars:

...you cannot 'have any paradigms' if according to your definition 'it includes agreements'... I may have a paradigm (as I do) as an individual scholar about which there are no general agreements; as an editor I take the field as.it is.

This response is interpreted as aparadigmatic because if each scholar adheres to a different paradigm (clearly possible based on his answer), no paradigm consensus could be reached within the field.

Thus, these last two comments reflect the current opinion regarding the development of speech Communication as described in the literature review. Pluralism of approach seems to be supported as an admirable characteristic of the field for these editors. overall, only two of the five editors gave aparadigmatic answers to guestion four. These conclusions lend further credence to the definition of Speech Communication as being in a preparadigmatic stage.

Question 5

If paradigms do not influence your editorial decisions and practices, what factors do guide your evaluation procedures? Five editors responded while only two were expected to respond (due to answering guestion one "yes" and question 
two "no"). However, again, responses did not conflict with previous answers. One editor explained an important criteria as the ability to argue one's case:

The ultimate criterion of evaluation is "so what?" Does this manuscript (study) involve a contribution to our knowledge/understanding of communication? If so, how much? In what way? Does the study lead to continued inquiry and programmatic inquiry into further knowledge/understanding of communication? (the where-do-we-go-from-here criterion).

Other evaluative factors cited by editors greatly resembled criteria listed in the ranking section of Part $A$ in the

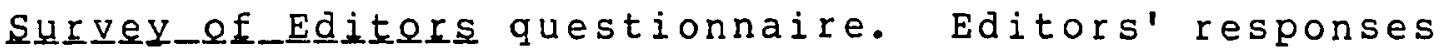
included:

We are seeking and favoring reports of studies that extend or challenge any established theory in the field.

Clarity and Originality.

Quality of theoretical development, quality of execution of design and procedures.

Thoroughness of investigations, validity of results...vividness of style, cogency of analyses, etc.

These responses clearly reflect the criteria for manuscript evaluation as identified in Part $A$ of the Survey of Editors. The question then is: To what degree do these responses reflect paradigm? To assess this question, the editor responses were analyzed in relation to the content categories constructed for this study. If these editor responses were not reflective of paradigm, they logically should not fit into the content categories. It seems all of the five responses can fit into the behavioristic category 
because they emphasize descriptive, empirical, scientific, etc. criteria for evaluation (see Content Categories, Chapter II). Thus, based on this question, all of these editors operate within the context of paradigm even if they do not identify it as such. Therefore, these responses add further support to the identification of Speech Communication as a preparadigmatic discipline.

Question 6

If paradigms do not influence your editorial decisions and practices, what factors do? Following survey directions, six editors responded to guestion six (answering question one "no" and guestion four). The answers were similar to those of guestion five, having two editors refer back to their misplaced answers in question five. Thus the Survey of Editors needs revision due to this overlap. Revision of this instrument would involve eliminating question six because of its confused redundancy. However, one editor who responded appropriately to question six stated:

My decisions are influenced by (1) whether the contributor is addressing a significant question in communication, (2) whether he or she devised an acceptable means of answering it, (3) whether the conclusions drawn from the inquiry are warranted and defensible, and (4) how well 1, 2, 3, are established in the written report.

While the previous answers (to question five) fit within the behavioristic content category, this response to question six appears broader and more inclusive. Therefore, this 
response could be considered a description of standards of scholarship, rather than paradigm.

Question 7

Do you think that paradigm development is important for the maturation of Speech Communication as an academic discipline? Why? Why not? The fundamental response from ten of the eleven journal editors was "no" (one editor did not respond to this question). While five of the ten answered "yes," they qualified their answers in such a way that two of them were evaluated as "no" conclusions. Therefore, their answers included seven "no's", two "yes's," and one equivocal.

The "yes" and "no" responses to this question took several forms. One form involved rejecting a "single" paradigm approach (although five editor responses echoed this theme, three are listed because the other two are merely redundant) :

Rigid agreements on paradigms can freeze a discipline. A single paradigm approach...is suicidal.

I do not subscribe (and I know of no others who do) to Thomas Kuhn's notion of a 'mature' discipline as one with a recognizable and specifiable single paradigm. Our academic discipline is multiparadigmatic, which I personally feel is more realistic and ultimately healthier than the quest for a single discipline [paradigm].

These responses can be thought of as the "don't fence me in" standard adopted by many in the field as evidenced in the Literature Review (e.g., diversity) and other editor 
responses to Part $B$ of this survey. In addition, these responses represent a resistance to the concept and connotation of the idea of paradigm. For these editors, paradigm infers 1 imitations/constraints on the practice of speech Communication. This inference to the concept may be due to the controversy surrounding the term "paradigm" just as it may be due to an overreaction on the discipline's part to being pigeonholed into a particular scholarly mode (e.g., Hovland school during the 1950's).

A second group of answers related to the idea that while paradigm may be used to describe science, it hardly applies to Speech Communication:

Only if the field predominately views itself as a science. So long as it does not, maturation will be measured against other criteria.

...I think it [paradigm] is a useful 'scientific' construct but not terribly useful in a discipline heavily dependent on criticism for its intellectual development.

These responses appear to present an approach to speech Communication that rejects the scientific model and defines very different functions for the discipline. Thus, for these editors, paradigm is meaningful only in the context of science.

Finally, responses included a belief that a commitment to some sort of theoretical perspective to guide research is important. In contrast to the first form of qualified responses, editors indicated a need for a variety of interests but that the individual researcher would decide on 
his/her commitment to a certain program of investigation. Editors remarked:

Doing research in the absence of a paradigm of awareness (if not commitment) is gathering data with little direction and without some ultimate purpose leading to cumulative development of understanding/ knowledge of communication. Without cumulative development we don't 'do research'; we only gather data.

The definition of paradigm given on page 4 is convoluted and ambiguous. Clearly, any academic discipline needs scholarship to develop, extend, and constantly challenge theoretical development in a discipline. If that is what 'paradigm development' means, yes it is important.

We need to do good research--in any way that is appropriate to our questions. If out of this a paradigm grows, ok. If not, that's ok too.

These last three comments, unlike the previous ones, embrace paradigm as a useful organizing principle. These responses seem to be in "agreement with" the concept that is related to Kuhn's discussion of paradigm (see Literature Review). Thus, paradigm for these editors can help the discipline develop, but only in certain respects. While two editors clearly support paradigm, the third was a bit more equivocal on the issue.

Thus, three patterns of response are evident in this question: a rejection of a single paradigm approach; a paradigm is useful but only in the context of science approach; and a belief that something is needed to organize and guide research in speech Communication. Only two editors believed that paradigm clearly could serve the third function. 
Therefore, paradigm is clearly seen as useful for discipline development by only two of the ten editors. These data underscore the confusion and disagreement with the concept of paradigm. While some editors believe an organizing principle is needed, they are not sure that it should be a paradigm. These responses also demonstrate the diversity of approach in the field le.g., preparadigmatic as evidenced in the behavioristic and humanistic dichotomy).

\section{Conclusions}

Based on the above data, hypothesis one is moderately supported. Question one demonstrated that four of the eleven editors agreed that paradigms exist in the discipline and are reflected in their journals (two were undecided) and five said "no" to question one. In addition, question three was used to test this hypothesis, with the results that five of the eleven editors were able to state there was more than one paradigm in the field (resulting in a $46 \%$ affirmation rate). Question four was also used as a test in that three of the five editors who said "no" to question one (no paradigms) actually ended up discussing information that could be interpreted as fitting the description of the behavioristic paradigm. These three responses plus the original four who answered "yes" to guestion one, make a total of seven editors actually discussing paradigm in speech Communication. This means that $63 \%$ of the eleven editors evidenced paradigm in their responses leading to the 
conclusion that paradigms, as described in this study, do in fact exist in the discipline. This is further confirmed by the fact that all identified paradigms fit into the a priori content categories (behavioristic/humanistic/other) as well as those responses given for "no paradigms" in question four. The fact that the editor responses (both those answers clearly identifying paradigms and those where paradigm was inferred; e.g., question four) fit into the content categories developed for this study suggests that speech Communication is in a preparadigmatic stage. Thus, based on the evidence supplied in answers to Part B of the survey of Editors, hypothesis one is accepted.

Finally, there was a recurring theme in answers to question two and question seven that bear repeating. Editors stated that while paradigms may be operative within the field, their main interest was in quality theoretical and investigative scholarship rather than whether a manuscript was in compliance with a particular paradigm. These views reflect similar conclusions drawn in the literature which suggests that while paradigms may operate within the field, they do not seem to get incorporated as organizing principles per se. Therefore, the functions that paradigm might serve in greater paradigm-developed fields such as Physics or Chemistry may not be desirable to the discipline of Speech Communication. 
The final chapter of this thesis includes a description of the limits of the study, gives a summary of the overall conclusions of the investigation, and offers suggestions for future research. 
CHAPTER IV

LIMITS OF THE STUDY, SUMMARY AND SUGGESTIONS

FOR FUTURE RESEARCH

Understanding what passes for knowledge and the dissemination of information within a scholarly community is important for the accumulation of knowledge and the development of disciplines. One significant contributor to knowledge diffusion is the scholarly journal, a formal communicative channel. This investigation sought to gain insight into the journal publication process within the field of speech Communication. In this portion of the thesis, limitations of the study are delineated, conclusions of the research project are recapitulated, and areas for future research are explored.

\section{LIMITATIONS OF THE STUDY}

This research project was exploratory in nature. Six general factors limited the results of this investigation.

(1) The fundamental external constraint on this project came from a lack of a body of literature on paradigm development in speech Communication. While several authors dealt with speculative and theoretical aspects of the issues 
raised in this thesis, other systematic research has not been done. For this reason, the writer consulted work conducted in the physical and social sciences to extract relevant variables that were then applied to speech Communication.

(2) Although Beyer's (1978) study influenced many of the parameters set for this research project, her basic premise of assessing universalistic and particularistic criteria for judging scholarly work were deemed too complex for an exploratory study of paradigm development in speech Communication. Instead, her hypotheses relating to testing degree of paradigm development as indicated by less difficulty in arriving at decisions for manuscript acceptance or rejection, length of article, manuscript revision, and length of time between manuscript submission and publication were incorporated into this study as sub-hypotheses. In addition, while she conducted a one-way analysis of variance to see if there were significant differences between high paradigm developed fields (Physics, $n=7$; Chemistry, $n=9$ ) and low paradigm developed fields (Sociology, $n=9$; Political Science, $n=6$ ), her sample size was so small that her tests of significance are open for debate. As a result, this study was limited to descriptive statistics and made no attempts to inferentially relate the means of one discipline to another. Because of the differences in statistical analyses, the data for Speech Communication are presented in 
conjunction with Beyer's results using means for both sets of data only.

(3) Beyer's conclusion that the number of journal pages devoted to book reviews as an indicator of paradigm development where more pages of book reviews inferred lesser paradigm development (Physics, 10.0 pages; Chemistry, 14.3 pages; Sociology, 97.6 pages; Political Science, 162.5 pages) is also open to question. One could speculate as to why book reviews are or are not included in journals. One reason could be journal space and priority of articles to book reviews due to limited funds for producing each volume. Another is that the physical sciences have journals devoted solely to book reviews and the social sciences have recently introduced such journals. Or, Beyer may have made a correct assessment, for as Hagstrom (1965) commented, "Formal communication in the sciences is primarily carried on through articles appearing in scientific journals. Books are also important, but not as important as they were, or as they are now in the social sciences" (p. 23). Clearly, based on Beyer's data, there is no direct way to infer the importance or unimportance of number of pages of book reviews to greater or lesser paradigm development. This limitation of Beyer's data is also a limit to this investigation.

(4) The format of Part B of the questionnaire was problematic in that editors did not follow directions correctly. While there is no way to know positively if this 
fact influenced the way editors responded to the questions, it appears that all relevant information was supplied.

(5) The definition of paradigm (contained in Part $B$ of the survey of Editors) was an internal limiting factor. Because of the kinds of information sought, it was necessary to supply a definition of paradigm for the editors to respond to. Any definition could potentially have posed problems for this study in that there is much debate surrounding the concept. of paradigm itself. Therefore, Rossiter's (1977) definition was chosen because it came from the speech Communication literature and was sufficiently explicit for editors to respond to the questionnaire. In addition, some of the editors found Rossiter's definition problematic and in their remarks explained why they did not like it. Because editors were allowed to respond to openended questions, the definition of paradigm offered in the survey did not necessarily constrain their responses. The definition seemed to be able to tap relevant information and the findings seemed to mitigate any limitations the definition may have imposed.

(6) Finally, the sample chosen for this project was limiting to the extent that only one component of the manuscript selection process were consulted. Editors were chosen because of their gatekeeping role and precedent set in other fields (cf. Beyer, 1978; Pfeffer, et al., 1977; Yoels, 1974; Crane, 1967). Although referees also share 
some of the manuscript selection responsibility, it was determined that the inclusion of referees was beyond the scope of this exploratory investigation. Further research on this topic should include the peer review system.

since external and internal limitations to research are part and parcel of the research process, the importance of the limits must be weighed in relation to the relevance of the findings. In this case, nearly all of the major Speech Communication journals were surveyed, and there was a 1008 return of the questionnaires. With the use of appropriate statistical profiles, the results of this investigation seem to accurately reflect speech Communication journal editors' opinions of paradigm development within the field.

\section{SUMMARY}

For the most part, hypotheses generated in this study to examine journal editorial policies and practices were affirmed. The first hypothesis was directed toward finding out journal editor opinion of paradigm development within the discipline of speech Communication and was tested in Part B of the Survey of Editors questionnaire. The overall conclusion was that the discussion of paradigm within the field is probably misdirected. This assertion is based on editors' presumed discomfort with the term paradigm to describe discipline development. While several editors believed speech Communication had paradigms, most felt that 
the idea of a single paradigm in the field was too restricting and therefore not desirable. Similarly, editors seemed to prefer to think of the field as broad-based and eclectic. This perspective, however, confounds another interest of these editors which was the perceived need of some sort of organizing principle for improving scholarship. These concerns were evidenced in editor expectations of the direction their respective journals should take and in their interest in research guidelines. Editor responses seemed to indicate that there was possibly more consensus in the field than they want to acknowledge. This conclusion was derived from the description by the editors of at least one paradigm in the field coupled with their vested interest in describing the field as diversified.

The second hypothesis and four sub-hypotheses tested in Part $A$ of the survey of Editors lent understanding to the degree of paradigm development within the field. In a few of the variables tested such as rate of manuscript acceptance, time lags between manuscript submission and publication, and the percentage of manuscripts refereed, speech Communication appeared to be closer to the physical sciences than were the social sciences. The overall conclusion, however, is that speech Communication has less paradigm development than do the social sciences. An interesting phenomenon within speech Communication was that there were more steps in the manuscript review process than there were 
in the other disciplines examined but that this did not hamper time efficiency to publication. That is, manuscripts submitted to Speech Communication journals were evaluated, revised, and published in less time than were manuscripts submitted to either Sociology or Political science journals. Regardless of whether one views paradigm as having merits or limitations as an organizing principle that could provide guidelines for research, Speech Communication journal editors seem to be looking elsewhere for such guidance. In this sense, understanding what is deemed viable for theoretical, methodological, and investigative work within the discipline should be explored. While we are neither truly a social nor a physical science, we are greatly influenced by disciplines that are. Therefore, understanding who we are and what we do can only help us improve on our scholarship and our maturation as a discipline. To this end, this study has made a small contribution to understanding the gatekeeping policies and practices. Obviously much more internal review is needed to determine the development and direction the field is and should be taking.

\section{FUTURE RESEARCH}

As an exploratory study into speech Communication, this research focused on getting a better understanding of the inner workings of the discipline. Much more critical reflection is needed for clarifying the production and use 
of knowledge within the field. Based on the broad conclusions arrived at during this investigation, strategies for future research might include the following:

(1) An examination of the peer review system within the discipline to add to further clarification/understanding of the gatekeeping function served. Especially useful would be the exploration of whether there is a difference in referee evaluation of manuscripts by specialist and nonspecialist reviewers.

(2) There should be research into rejected manuscripts: Why was it (the manuscript) rejected, how many times was it rejected, did the author ever get it published? If not, why not? This information could be useful in assessing standards for scholarship, and whether or not innovation is getting a fair hearing within the field.

(3) Informal communication channels such as conferences and association meetings should be examined for clarification of their impact on the production, diffusion and use of knowledge within the discipline (Hagstrom, 1965).

(4) Inquiry into the role books play within the knowledge exchange system of the field would also help to explain the character of the discipline (Beyer and snipper, $1974)$.

(5) Further research of the behaviorist/humanist dichotomy should be undertaken of a representative sample (e.g., professors, versus this study's editors) to assess 
the efficacy of these paradigms as descriptions of the discipline.

(6) How do the various journals within the discipline operate? A case study of a journal, tracking the entire decision-making processes of the editor, could shed light on the scope of his/her gatekeeping function and the influence of his/her decisions on what is published (Smigel and Ross, 1970)

(7) Since speech Communication had only a slightly better acceptance rate (198) than did Sociology and Political science (both at 13\%), investigation as to whether articles are rejected in speech Communication on a Type I (false positive) or Type II (false negative) basis is important for understanding the discipline's receptivity to innovation (Beyer, 1978; Zuckerman and Merton, 1970).

While research similar to that proposed above has been done in other fields, monitoring our own knowledge creation, diffusion and utilization can only aid in our growth and development as a discipline. Since "communication" is our focal point, we must examine the theoretical and methodological messages we send and receive. From this sort of evaluation, then, we will be able to continue to build and maintain our community of scholars and improve the quality of knowledge we produce. 


\section{A SELECTED BIBLIOGRAPHY}

Barbour, Ian G. Myths, Models and Paradigms: A Comparative Study in science and Religion. New York: Harper and Row Publishers, 1974 .

Benson, Thomas w. "On Getting Published: An Editor's Perspective," The Pennsylvanias_speech__com municaㅗ도으 Annual, 35 (1979), 9-14.

Berardo, Felix M. "The Publication Process: An Editor's Perspective," Journal of Marriage and the Family, 43 $(1981), 771-779$.

Beyer, Janice M. and Ruben snipper. "Objective Versus Subjective Indicators of Quality in Graduate Education," Sociology of Education, 47 (1974), 541557 .

Beyer, Janice M. "Editorial Policies and Practices Among Leading Journals in Four Scientific Fields," The Sociological ouarterly, 19 (1978), 66-88.

Bochner, Arthur P. "Wither Communication Theory and

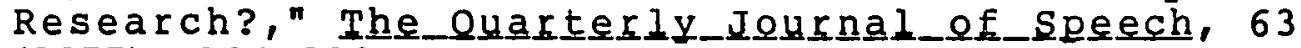
$(1977), 324-332$.

Borden, George A. and John D. Stone. Human Communication:

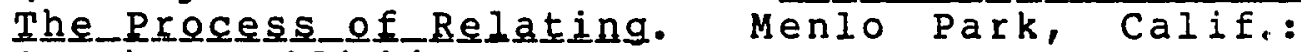
Cummings Publishing Company, Inc., 1976.

Bottomore, Tom. "Competing Paradigms in Macrosociology." In Annual Review of Sociology, pp. 191-202. Edited by Alex Inkeles, James Coleman, and Neil Smelser. Palo Alto, Calif.: Annual Reviews, 1975.

Bowers, John Waite and James J. Bradac. "Issues in Communication Theory: A Metatheoretical Analysis." In Communication Yearbook 5, pp. 1-27. Edited by Michael Burgoon. New Brunswick, New Jersey: Transaction Books, 1982 .

Browning, L. D. "A Grounded organizational Communication Theory Derived from Qualitative Data," Communication Monographs, 45 (1978), 93-109. 
Campbell, Paul. "An Overview of four Common Errors in Reporting Statistical Inforintion in Journal Articles," Journa1 of Marriage and the Famiaj, 43 $(1981), 285-292$.

Carroll, Michael P. "Considerations on the Analysis of Variance Paradigm," Pacific Sociologicà Reyiesw, 15 $(1972), 443-459$.

Chambers, J. M. and Agnes M. Herzberg. "A Note on the Game of Refereeing," Applied Statistics, 17 (1968), 260263 .

Cole, stephen and Jonathan R. Cole. "Scientific Output and Recognition: A study in the operation of the Reward System in Science," American Socjologist, 32 (1967), 377-390.

University of Chicago press, 1973.

Crane, Diane. "The Gatekeepers of Science: Some Factors Affecting the selection of Articles for Scientific Journals," American Sociologist, 2 (1967) 195-201. Scientific communities.
Chicago Press, 1972 .

Cronen, Vernon E. and Leslie K. Davis. "Alternative Approaches for the Communication Theorist: Problems in the Laws - Rules - Systems Trichotomy," Human cimmunication Research, 4 (1978), 120-128.

Cronkhite, Gary and Jo Liska. "Introduction," Western Journal of Speech Communication, 41 (1977), 3-8.

Cushman, Donald P. "The Rules Perspective as a Theoretical Basis for the study of Human communication," Communication Quarterly, 25 (1977), 30-45.

and W. Barnett Pearce. "Generality and Necessity in Three Types of Theory About fiuman Comminication with special Attention to Rules Theory," Human Communication Research, 3 (1977), 344-353.

Dance, Frank E. X. "Preface." In Human communication Theory: Comparative Essays, pp. ix-xi\% edited by Frank E. X. Dance. New York: Harper ana Row, Publishers, 1982. 
Delia, Jesse G. "Alternative Perspectives for the Study of Human Communication: Criticue and Response," Communication ouarterly, 25 (1377), 46-62.

and Lawrence Grossberg. "Interpretation and Evidence," Western Jolirnai of Speech Communication, 41 $(1977), 32-42$.

"The Future of Graduate Education ir. Speech Communication: A Personal perspective," Cummujication Education, 28 (1979), 271-281.

B. J. O'Reefe and D. J. O'Keefe. "The Constructivist Approach to Communication." In Human Communi-

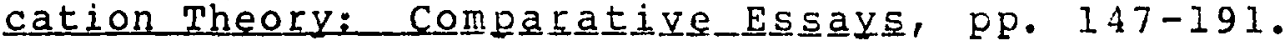
Edited by Frank E. X. Dance. New York: Harper and Row Publishers, 1982.

Denisoff, R. S., O. Callahan and M. H. Levine. Theoriesand

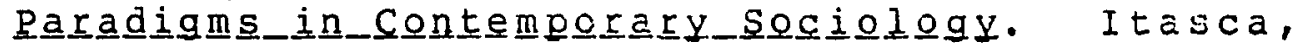
Illinois: F. E. Peacock, 1974.

Donohue, William A., Donald P. Cushman and Robert E. Nofsinger. "Creating and Confronting Social order: A Comparison of Rules Perspectives," Western Journal of Speech Communication, $44(1980), 5-19$.

Douglas, Jack D. "The Rhetoric of Science and the origirs of Statistical Thought: The Case of Durkheim's Suicide." In The phenomenon of Sociology, pp. 44-57. Edited by Edward A. Tiryakian. New York: AppletonCentury-Crofts, 1971.

Eckberg, Douglas Lee and Lester Hill, Jr. "The Paradigm Concept and Sociology: A Critical Review," American Sociological Review, 44 (1979), 925-937.

Effrat, Andrew. "Power to the Paradigms: An Editorial Introduction," Sociological Inquiry, 42 (1972), 3-34.

Fisher, Aubrey B. "Evidence Varies with Theoretical Perspective," Western Journal of Speech Communication, $41(1977), 9-19$.

"In Retrospect," Western Journal of Speech communication, 41 (1977), 43-49.

"The Pragmatic Perspective of Human Communication: A View from System Theory." In Human Communi-

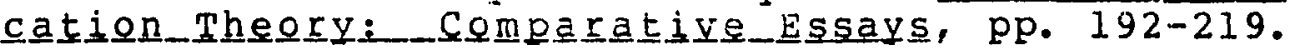
Edited by Frank E. X. Dance. New York: Harper and Row Publishers, 1982. 
Friedrich, Gus. "From the Editor," Communication Education, $30(1981), 448$.

Friedrichs, Robert W. A Sociology of Sociology. New York: Free Press, 1970 .

Garfield, Eugene. "Publishing Referees' Names and Comments Could Make A Thankless and Belated Task A Timely and Rewarding Activity." In Essays of An Informastion scientist, 1962-1973, Vol. 1, pp.435-437. Edited by Eugene Garfield. Philadelphia: ISI Press, 1977.

Gaston, J., H. R. Lantz and C. R. Snyder. "Publication Criteria for Promotion in Ph.D. Graduate Departments," American Sociologist, 10 (1975), 239-242.

Glaser, B. W. and A. M. Strauss. The Discovery of Grounded Theory: Strategies for oualitative Research. Chicago: Aldine, 1967.

Goodall, H. Lloyd, Jr. and Gerald M. Phillips. "Assumptions of the Burden: Science or Criticism?," communication Quarterly, 29 (1981), 283-296.

Gordon, Michael D. "The Role of Referees in Scientific communication." In The Psychology of Written communication: Selected Readings, pp. 263-275. Edited by James Hartley. London: Kogan Page, 1980.

Gouran, Dennis s. "Speech Communication Its Conceptual Foundation and Disciplinary status," communication Education, 26 (1979), 1-8.

Grossberg, Lawrence and Jesse G. Delia. "In Response," Western Journal of Speech communication, 41 (1977), 53-56.

Gutting, Gary. "Introduction." In Paradigms and RevoIutions: Appraisals and Applications of Thomas Kuhn's Philosophy of science, pp. 1-21. Edited by Gary Gutting. Notre Dame: University of Notre Dame Press, 1980 .

Hagstrom, Warren 0 . The scientific Community. New York: Basic Books, 1965.

Harper, Nancy L. Human Communication Theory: The History of a Paradigm. Rochelle Park, New Jersey: Hayden Book Company, Inc., 1979. 
Hawes, Leonard C. "Alternative Theoretical Bases: Toward A Presuppositional Critique," communication ouarteriy, $25(1977), 63-68$.

Jones, Robert. "Rights, Wrongs and Referees," New Scientist, 21 March 1974, 758-759.

Kerlinger, Fred N. Foundations of Behavioral Research. 2nd edition. New York: Holt, Rinehart and Winston, Inc., 1973.

King, M. D. "Reason, Tradition, and the Progressiveness of Science." In Paradigms and Revolutions: Appraisals and Applications of Thomas Kuhn's Philosophy of Science, pp. 97-116. Edited by Gary Gutting. Notre Dame: University of Notre Dame Press, 1980.

Kucklick, H. "A 'Scientific Revolution': Sociological Theory in the united States," Sociological Inguiry, 43 $(1972), 2-22$.

Kuhn, Thomas s. The Structure of scientific Revolutions. Chicago: University of Chicago Press, 1962.

- The Structure of Scientific Revolutions. 2nd edition. Chicago: University of Chicago Press, 1970.

Lehman, T. and R. T. Young. "From Conflict Theory to Conflict Methodology: An Emerging Paradigm for Sociology," Sociological Inquiry, 44 (1974), 15-28.

Liska, Jo and Gary Cronkhite. "Epilogue for Apologia: on the Convergent Validation of Epistemologies," Western Journal of Speech Communication, 41 (1977), 57-65.

Littlejohn, stephen $W$. "An Overview of Contributions to Human Communication Theory from Other Disciplines." In Human Communication Theory: Comparative Essays, pp. 243-285. Edited by Frank E. X. Dance. New York: Harper and Row Publishers, 1982.

Lockwood, Willard A. "The Decision to Publish: Scholarly Standards." In scholars and Their Publishers, pp. 517. Edited by Weldon A. Kefauver. New York: The Modern Language Association of America, 1977.

Lodahl, Janice Berger and Gerald Gordon. "The Structure of Scientific Fields and the Functioning of University Graduate Departments," American Sociological Review, 37 (1972), 57-72. 
- "Funding the Sciences in University Departments," Educational Record, 54 (1973), 74-82.

MacRae, Duncan Jr. The Social Function of Social Science. New Haven: Yale University Press, 1976.

McCutchen, Charles. "An Evolved Conspiracy," New Scientist, 29 April 1976, 225.

Mahoney, Michael J. Scientist as Subject: The Psychological Imperative. Cambridge, Mass.: Ballinger Publishing Co., 1976.

Marlier, John T. "What Is speech Communication Anyway?," Communication Education, 29 (1980), 324-327.

Masterman, Margaret. "The Nature of A Paradigm." In criticism and the Growth of Knowledge, pp. 59-89. Edited by Imre Lakatos and Alan Musgrave. Cambridge: Cambridge University Press, 1970.

Merton, Robert $k$. "The Matthew Effect," Science, 159 $(1968), 56-63$.

Miller, G. R., and C. R. Berger. "On keeping the Faith in Matters Scientific," Western Journal of Speech communication, 42 (1978), 44-57.

Miller, G. R. "Tis the Season to Be Jolly: A Yuletide 1980 Assessment of Communication Research," Human Communication Research, 7 (1981), 371-377.

Mulkay, M. J. The Social process of Innovation: A study in the Sociology of Science. London: MacMillian Press Ltd., 1972.

"Three Models of Scientific
Sociological Review, 23 (1975), 509-526.

Mullins, Carolyn J. A Guide to Writing and Publishing in the Social and Behavioral Sciences. New York: John wiley and Sons, 1977.

Mullins, Nicholas C. Science: Some Sociological Perspectives. Indianapolis: The Bobbs-Merrill Company, Inc., 1973.

O'Keefe, Daniel J. "Logical Empiricism and the study of Human Communication," Speech Monographs, 42 (1975), 171-183. 
Palmer, Lane. "The Scientific Method: A Writer's Best Friend," The Humanist, 42 (1982), 29+.

Paulson, Stanley F. "Speech Communication and the Survival of Academic Disciplines," Communication Education, 29 $(1980), 319-323$.

Pearce, W. Barnett. "Consensual Rules in Interpersonal Communication: A Reply to Cushman and whithng," Journal of Communication, 23 (1973), 160-168.

"Metatheoretical Concerns in Communication," communication Quarterly, 25 (1977), 3-6.

"The 'Ecumenical Spirit': A Reply to Miller and Berger," Western Journal of Speech Communication, 42 (1978), 276-281.

Pfeffer, Jeffrey, Antony Leong, and Katherine Strehl. "Paradigm Development and Particularism: Journal Publication in Three Scientific Disciplines," Social Forces, 55 (1977), 938-951.

Phillips, Derek L. Knowledge From What?; Theories and Methods in Social Research. Chicago: Rand McNally and Company, 1971.

Phillips, Gerald M. "Science and the study of Human Communication: An Inquiry from the other side of the Two Cultures," Human Communication Research, 7 (1981), 361-370.

Remus, William. "Strategies for a Publish or Perish World Or Why Journals Are Unreadable," Interfaces, 8 (1977), 64-69.

- "Why Academic Journals Are Unreadable: The Referees' Crucial Role," Interfaces, 10 (1980), 87-90.

Ritzer, George. Sociology: A Multiple Paradigm Science. Boston: Allyn and Bacon, 1975.

Rogers, Everett M. "The Empirical and the Critical Schools of Communication Research." In Communication Yearbook 5. pp. 125-144. Edited by Michael Burgoon. New Brunswick, New Jersey: Transaction Books, 1982 .

Rosenthal, Robert. "The 'File Drawer Problem' and Tolerance for Null Results," Psychological Bulletin, 86 (1979), 638-641. 
Rossiter, Charles M. "Models of Paradigmatic Change," Communication Quarterly, 25 (1977), 69-73.

Ruben, Brent D. and John M. Wiemann. "The Diffusion of Scientific Information in the communication Discipline: Conceptualization and Proposition," Communication Quarterly, 27 (1979), 47-53.

Sanders, Robert E. "The Question of a Paradigm for the Study of Speech-Using Behavior," The Quarterly Journal of Speech, 59 (1973), 1-10.

and L. W. Martin. "Grammatical Rules and Explanation of Behavior," Inquiry, 18 (1975), 65-82.

Scheidel, Thomas M. "Evidence Varies with Phases of Inquiry," Western Journal of Speech Communication, 41 $(1977), 20-31$.

"Afterthoughts," Western Journal of Speech communication, 41 (1977), 50-52.

Sherman, L. W. "Uses of the Masters," American Sociolcrist, $9(1974), 176-181$.

Silverman, Robert J. "The Education Editor as Futurist," Teachers College Record, 77 (1976), 473-493.

"The Education Journal Editor: A Portrait," Boston University Journal of Education, 158 (1976), 39-68.

Smigel, Erwin O. and H. Laurence Ross. "Factors in the Editorial Decision," American Sociologist, 5 (1970), 19-21.

Steward, Larry A. "Attitudes Toward Communication: The Content Analysis of Interviews with Eight Reticent and Eight Non-Reticent College students." Diss. Pennsylvania State University, 1968.

Stone, Phillip J., Dexter C. Dunphy, Marshall S. Smith and Daniel M. Ogilvie. The General Inquirer: A Computer Approach to Content Analysis. Cambridge, Mass.: The M.I.T. Press, 1966.

Tucker, Raymond K., Richard L. Weaver II, and Cynthia

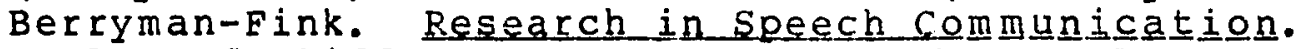
Englewood Cliffs, New Jersey: Prentice-Hali, Inc., 1981. 
Wall, Edward C. "Ruminations on Becoming Published." In Directory of Publishing opportunities in Journals and eㅗ도으모도고, pp. ix-xi. 5 th edition. Chicago: Marquis Academic Media, Marquis Who's Who, Inc., 1981.

Walsh, D. "Sociology and the Social World." In New Directions in sociological Theory, pp. 15-36. Edited by Paul Filmer, Michael Phillipson, David Silverman, and David Walsh. Cambridge, Mass.: M.I.T. Press, 1972.

Warwick, Donald P. and Charles A. Lininger. The Sample Survey: Theory and practice. New York: McGraw-Hill Book Company, 1975.

Westhues, Kenneth. "Class and Organization as Paradigms in Social Science," American Sociologist, 11 (1976), 3848.

Williams, L. Pearce. "Normal science, scientific Revolutions and the History of Science." In Criticism and the Growth of knowledge, pp. 49-50. Edited by Imre Lakatos and Alan Musgrave. Cambridge: Cambridge University Press, 1970.

Yoels, William C. "Destiny or Dynasty: Doctoral Origins and Appointment Patterns of Editors of the American Sociological Review," American Sociologist, 6 (1971), 134-139.

"The structure of scientific Fields and the Allocation of Editorships on Scientific Journals: Some Observations on the Politics of knowledge, "The Sociological Quarterly, 15 (1974), 264-276.

Ziman, John. Public Knowledge: An Essay Concerning the

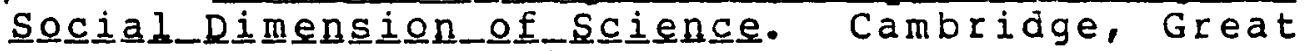
Britain: Cambridge University Press, 1968.

The Force of Knowledge: The Scientific Dimension of Society. Cambridge, Great Britain: Cambridge University Press, 1976.

Zuckerman, Harriet and Robert k. Merton. "Patterns of Evaluation in science: Institutionalisation, Structure, and Functions of the Referee system," Minerva, 9 (1971), 66-100. 
APPENDIX A

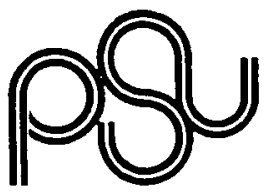

November 10, 1982

Dear Professor

Attached to this letter you will find a portion of a questionnaire that

is part of my thesis project. I would appreciate your assistance in determining the clarity and validity of the questions I have written. Would you take a few moments to answer the questions as directed. Your completion of this questionnaire will constitute a pilot study of the instrument.

In completing these questions, please act as if you were an editor for a major Speech Communication journal. If you have any suggestions or comments, please put them on the blank sheet attached to the questionnaire.

As I am under strict time constraints, it is essential that the questionnaire is completed and submitted to Dr. Larry Steward by Tuesday, November $16,1982$.

I thank you for your cooperation and I look forward to your comments.

Cordially,

Laurie Houghton

Graduate Student 
Part B

Please answer the following question fully.

Roseiter has interpreted paradigm to moan.

- world riew sbout how theoretical work should be done in a partleular subject aren which is ahared by those who actually do theoretlcal work in that subject area. It Includes areements about, aseumptione about the nature of the subject areas or phenomenon about which theory is belng built, variebles which are most lmportant for atudy to underatand the phenomenon about which theory is being bullt, and acceptable nethods for aupporting essertions about the phemonenon about which theory is being bullt. $(1977,70)$

Please respond to the rest of the questionneire bearing this definition In mind.

1. That is your asaessment of paradigm development within the discipline of Speech Communication? Do you think wo have a paradigm(B)?

- If "yes" go to question 2. If no" go to question 4.

2. If you agree that there are paradigms operating within the freld. would you label 1t/them and describe their philosophical underpinnings? That 15, wat makes the paradigms (B) you describe distinctive?

GO TO QUESTION 3.

Rossiter. Charles M. "Models of Paradigmat1c Chango" Communication Quarterly (ninter 1977. 25,69-73) 
3. Former Journal editor Felix Berardo of the Journal of Marringe and the Pamily contends that "the formula of a successful author is a quality manuscript based on research grounded in an established paradigm (1981:771). Do paradigms influence your editorial decisions and practices? yes "yes" in what ways? no If "no" go to question 5 . GO TO QUESTION 7 .

4. If you believe there are no paradigms within the field of Speech Communication, how did you come to that conclusion? That is, what makes you think there are no paradigms?

GO TO QUESTION 6 .

5. If paradigms do not influence your editorial decisions and practices. what factors do gulde your evaluation procedurea?

GO TO QUESTION 7 .

Berardo, Pellx M. "Tre Publication Process An Editor'g Perspective" Journal of Merriage and the Pam11y (November 1981, 43.771-779) 
6. If paradigms do not influence your editorial decisions and practices, what factors do?

GO TO QUESTION 7 .

7. Do you think that paradigm development is important for the maturation of Speech Communication as an academic discipline? Why? Why not?

THANK YOU FOR PARTICIPATING IN THIS SURVEY. 


\section{APPENDIX $C$ \\ OVERVIEW OF PHONE CONVERSATION}

Hello--

My name is Laurie Houghton and I am a graduate student in the Speech Communication Department at Portland State University in Portland, Oregon.

I am contacting you because I am conducting a survey to gather information regarding editorial practices for my master's thesis. The study focuses on the degree to which journals in the field of Speech Communication reflect conceptual agreements and differences concerning manuscript acceptance and rejection. I am also interested in your views on the idea of paradigm development within the discipline.

As the editor of you are in a unique position to provide the necessary information concerning editorial practices in our field. I am calling to request your participation in my study.

I would like to send you a short questionnaire that will take approximately 20 minutes of your time to complete.

Also, I would like to mention that the sample size of this study consists of 11 participants. So... in a very real sense you are one of very few who can provide the valuable information needed to conclude this research project.

I'll be sending the questionnaire by registered mail to insure its safe delivery. What address would you like me to send it to? A response at your earliest convenience would be greatly appreciated.

Thank you. 
APPENDIX D
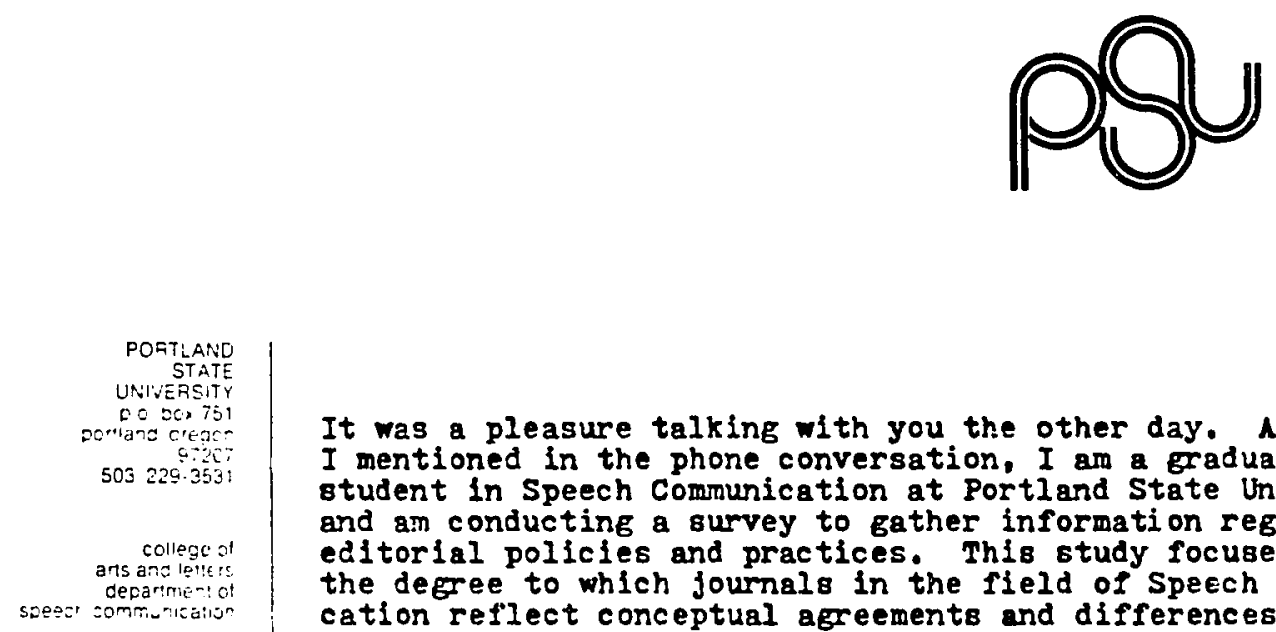

It was a pleasure talking with you the other day. As I mentioned in the phone conversation. I am a graduate student in Speech Communication at Portland State University and am conducting a survey to gather information regarding editorial policies and practices. This study focuses on the degree to which Journals in the fleld of speech Communication reflect conceptual agreements and differences concerning manuscript acceptance and rejection. In addition, an integral part of this study includes identifying editor's views on the idea of paradigm development within the discipline of Speech Communication.

Because Speech Communication is still in its formative stage as an academic discipline, the sample selected for research is relatively small, eleven participants in total. Therefore, jour full participation in this study would be greatiy appreciated and would significantly add to the body of knowledge concerning the field as a whole. Although all joumals will be ldentified, answers will be coded for anonymity. If you are interested in the findings of this study you can so indicate by marking the response box provided on the last page of the questionnaire. Study results will be forwarded during the third week of January, 1983.

If you have any questions, please feel free to contact we at (503) 245-1725. Thank you for your time and participation in this study. I look forward to receiving your response.

Cordially,

Laurle A. Houghton, Graduate Student Department of Speech Communication Portland State University Portland, oregon

Enclosures 


\section{APPENDIX E}

\section{SURVEY OF EDITORS}

Age

Highest Degree Achieved
Academic Specialty Institution of Degree

PAR?

In terms of the articles sent to you for publication during 1981. would you specify the:

Current rate of acceptance of accepted manuscripts

\section{\% require no revision}

\% require minor revision, not resubmitted to referees

\% require minor revision, resubmitted to referees

* require major revision, resubmitted to referees

क require major revision, treated like new submission

Refereeing process

6 of manuscripts refereed

\% of manuscripts not refereed that are rejected

* of manuscripts refereed by more than one referee

\% of manuscripts unanimously accepted by referees

\% of manuscripts unanimously rejected by referees

\% of manuscripts leading to referee disagreement

What are the procedures you use for handing referee disagreement? 
$-2-$

\section{Time periods for publicetion}

number of months between submission and publication of a typical anuscript

shortest interval to publication

number of months between decision to publish and actual publication

number of months required for publication process exclusively

Please rank, using the following scale, the importance of criteria

used in considering manuscripts, where, (1) = not at all

(2) = somewhat important

(3) = very leportant but not eseential

(4) = essential

originality

logleal rigor

mathematical/statistical rigor

compatibility with generally accepted disciplinary ethics

clarity and conclseness of witing style

relevance to current areas of research

theoretical sienificance

positive findings

negative results

replicability

coverage of significant ilterature

applicability to practical or applied problems 


\section{$-3-$}

\section{General publication informetion}

number of manuscripts submitted annually

tenure of present editor

tenure of previous editor

What was your original intention for the direction and focus of your

journal that you wished to display upon assuming your editorship?

What obstacles, if any. have you encountered in the realization of the above?

Can you identify any changes or modifications in your original intent? 
$-4-$

PART B

Please answer the following questions fully. If further space is required to complete your answer, please use the back of the questionnaire pages and number your response according to the question you are answering.

Rossiter has interpreted paradigm to mean.

... a world view about now theoretical work should be done in a particular subject area which is shared by those who actually do theoretical work in that subject area. It includes agreements about, assumptions about the nature of the subject areas or phenomenon about which theory is being built, variables which are most important for study to understand the phenowenon about which theory is being built; and acceptable methods for supporting assertions about the phenomenon about wich theory is being built . (1977.70).

Please respond to the rest of the questionnaire bearing this definition in mind.

1. What 1s your assessment of paradigm development within the discipline of Speech Communication as reflected in your journal?

Do you think we have any paradigms? Yes If "yes" go to question 2. No

If "no" go to question 4.

2. Pormer journal editor Pelix Berardo of the Joumal of Marriage and the Pamily contends that "the formula of a successful author is a quality manuscript based on research grounded in an established paradigm" (1981.771). Do paradigms influence your editorial decisions and practices?

Yes

If "yes." In what ways?

No

If "no" go to question 5.

Berardo, Pelix M. "The Publication Process, An Editor'B Perspective" Joumal of Karriage and the Pamily (November 1981, 43:771-779).

Rossiter: Charles M. "Models of Paradigmatic Change" Communication ouarterly (Ninter 1977. 25:69-73). 


$$
-5-
$$

3. If you agree that there are operative paradigms as indicated in question 1, would you label each one and describe its philosophical underpinnings? That 18, what makes the paradigm you describe distinetive?

GO TO QUESTION 7 .

4. If you believe there are no paradigms within the field of speech Communication, could you briefly outline your reasons for that conclusion?

GO TO QUESTION 6.

5. If paradigms do not influence your editorial decisions and practices. what factors do guide your evaluation procedures? 
$-6-$

6. If paradigms do not influence your editorial decisions and practices, what factors do?

GO TO QUESTION 7.

7. Do you think that paradigm developwent is important for the maturation of Speech Communication as an academic discipline? Why? Why not?

THANK YOU FOR PARTICIPATING IN THIS SURVEY.

I am interested in the resalts of this study. Please send me the oummary report. 